\title{
Age-Induced Changes in Mu Opioid Receptor Signaling in the Midbrain Periaqueductal Gray of Male
}

\section{and Female Rats}

Evan F. Fullerton ${ }^{1}$, Mary C. Karom ${ }^{1}$, John M. Streicher ${ }^{2}$, Larry J. Young ${ }^{3}$, and Anne Z. Murphy ${ }^{1}$

${ }^{1}$ Neuroscience Institute, Georgia State University, Atlanta, GA, 30303, USA

${ }^{2}$ Department of Pharmacology, College of Medicine, University of Arizona, Tucson, AZ 85724, USA.

${ }^{3}$ Department of Psychiatry and Behavioral Sciences, Emory University School of Medicine, Atlanta, GA, 30322 USA

\section{Corresponding author:}

Anne Z. Murphy, Ph.D.

Neuroscience Institute, Georgia State University

100 Piedmont Ave SE, Atlanta, Georgia, 30303, United States

Tel: 404/413-5332

Email: amurphy@gsu.edu

Declarations of interest: JMS has an equity stake in Botanical Results, LLC and is co-founder and equity holder in Teleport Pharmaceuticals, LLC. No company products or interests were tested in this study. 


\section{Highlights:}

- $\quad$ Aged males and females (adult and aged) exhibit reduced vIPAG $\mu$-opioid receptor binding potential compared to adult males.

- Aged males and females (adult and aged) exhibit reduced opioid-induced vIPAG G-protein activation compared to adult males.

- Aged males and females (adult and aged) exhibit reduced vIPAG MOR mediated cAMP inhibition compared to adult males.

- Aged rats (males and females) exhibit increased vIPAG mRNA expression of Regulator of GProtein Signaling (RGS) proteins RGS4 and RGS9-2 compared to adult rats (males and females), which may explain the reduced receptor signaling observed in aged animals.

- These coordinate decreases in opioid receptor signaling may explain the previously reported reduced potency of opioids to produce pain relief in females and aged rats. 
1 Abstract: The analgesic effects of opioids are attenuated in aged rats. Opioids such as morphine have

2 decreased analgesic potency (but not efficacy) in aged rodents compared to adults; however, the neural

3 mechanisms underlying this attenuated response are not yet known. The present study investigated the

4 impact of advanced age and biological sex on opioid signaling in the ventrolateral periaqueductal gray

5 (VIPAG) in the presence of chronic inflammatory pain. Assays measuring mu-opioid receptor (MOR)

6 radioligand binding, GTP $\gamma$ S binding, receptor phosphorylation, cAMP inhibition, and regulator of G-

7 protein signaling (RGS) protein expression were performed on vIPAG tissue from adult (2-3mos) and

8 aged (16-18mos) male and female rats. Persistent inflammatory pain was induced by intraplantar

9 injection of Complete Freund's Adjuvant (CFA). Adult males exhibited the highest MOR binding potential

10 and the highest G-protein activation (activation efficiency ratio) in comparison to aged males and

11 females (adult and aged). No impact of advanced age or sex on MOR phosphorylation state was

12 observed. DAMGO-induced CAMP inhibition was highest in the vIPAG of adult males compared to aged

13 males and females (adult and aged). vIPAG levels of RGS4 and RGS9-2, critical for terminating G-protein

14 signaling, were assessed using RNAscope. Adult rats (both males and females) exhibited lower levels of

15 vIPAG RGS4 and RGS9-2 mRNA expression compared to aged males and females. The observed age-

16 related reductions in vIPAG MOR binding potential, G-protein activation efficiency, and cAMP inhibition,

17 along with the observed age-related increases in RGS4 and RGS9-2 vIPAG expression, provide potential

18 mechanisms whereby the potency of opioids is decreased in the aged population. These results have

19 significant implications for pain management in this population.

21 Keywords: chronic pain; opioid signaling; pharmacology; advanced age; sex differences; mu-opioid

22 receptor 
25 Chronic pain is a debilitating condition that contributes to mental health disorders, disability, and 26 increased risk of premature death (Domenichiello and Ramsden, 2019; Patel et al., 2013). More than 50\% 27 of individuals aged 65 and over suffer from chronic pain, and as the United States population rapidly ages, 28 the development of effective strategies for chronic pain management for this demographic is imperative 29 (Dahlhamer, 2018). Opioids, including morphine and fentanyl, are commonly prescribed analgesics for the 30 management of chronic pain (Manchikanti et al., 2010; Sullivan et al., 2010), but effective dosing strategies

31 for the elderly remain ill-defined, due in large part to a dearth of knowledge regarding the impact of

32 advanced age on opioid signaling and analgesia.

33 Clinical studies examining pain management in the elderly are challenging; co-morbid conditions such as

34 diabetes and high blood pressure, and participant use of concomitant medications affect patient

35 outcomes, contributing to difficulties in the interpretation of results (Naples et al., 2016; Prostran et al.,

36 2016). Additionally, there exist age- and sex-related individual differences in the likelihood of reporting

37 pain in a clinical setting which may lead to misrepresentations of analgesic efficacy (Dampier et al., 2013;

38 Reddy et al., 2012). Particularly, aged populations are known to underreport pain due to fears of

39 institutionalization and concerns with addiction and overdose (Reddy et al., 2012).

40 Using a preclinical model of persistent inflammatory pain (intraplantar Complete Freund's Adjuvant;

41 (CFA)), we have previously reported a significant impact of age and sex on morphine potency. Specifically,

42 we showed that aged rats (18mos) exhibit a decreased morphine potency compared to adults ( 2 mos), with

43 aged males requiring greater than $2 x$ the concentration of morphine than their adult counterparts to

44 produce equivalent analgesia (Fullerton et al., 2021). Similar results have been reported in prior preclinical 45 studies, suggesting that aged rodents require higher doses of opioids to produce antinociception (Kavaliers 
46 et al., 1983; Kramer and Bodnar, 1986; Webster et al., 1976). The mechanisms underlying the attenuation

47 of opioid potency in the aged population are currently unknown.

48 Morphine-induced analgesia is mediated primarily via binding to $\mu$-opioid receptors (MOR), prototypical

49 G-protein coupled receptors (GPCRs) located predominantly on neuronal cell membranes (Martin, 1963;

50 Wolozin and Pasternak, 1981). Following agonist binding, coupled G-proteins undergo a conformational

51 change in which the guanosine diphosphate (GDP) bound to the inactive alpha subunit is replaced by

52 guanosine triphosphate (GTP), activating the subunit and promoting opioid signaling through interaction

53 with downstream effectors (Senese et al., 2020). MORs are coupled to a family of G-proteins called Gi/o

54 that signal via inhibition of adenylyl cyclase and subsequently decrease cyclic adenosine monophosphate

55 (cAMP) (Koehl et al., 2018; Bouchet et al., 2021). This G-protein signaling is downregulated or terminated

56 by Regulator of G-Protein Signaling (RGS) proteins, which act as GTPase activating proteins (GAPS),

57 hydrolyzing the active GTP back into GDP and terminating downstream signaling (Gerber et al., 2016). RGS

58 proteins, particularly RGS4 and RGS9-2, have been previously implicated in opioid-mediated G-protein

59 signaling, and have been shown to attenuate analgesia (Garnier et al., 2003; Psifogeorgou et al., 2007;

60 Avrampou et al., 2019; Senese et al., 2020). A primary target of MOR downstream signaling is the effector

61 adenylate cyclase (AC). AC enzymatically converts adenosine triphosphate (ATP) to the excitatory second

62 messenger cyclic adenosine monophosphate (CAMP). MOR binding inhibits AC, thereby reducing cAMP

63 expression, facilitating neuronal hyperpolarization, and promoting analgesia (Santhappan et al., 2015). Like

64 other G-protein coupled receptors, MOR signaling is subject to desensitization via the cellular mechanism

65 of receptor phosphorylation, which limits agonist binding and recruits arrestin proteins, and thus

66 attenuates opioid signaling. (Zhang et al., 1996; Yu et al., 1997; Groer et al., 2011).

67 The present studies test the hypothesis that the observed age-induced reduction in morphine potency in

68 the presence of chronic pain is mediated by changes in MOR signaling within the midbrain periaqueductal 
69 gray, a CNS region critical for the opioid modulation of pain. (Basbaum et al., 1976; Behbehani and Fields,

70 1979; Morgan et al., 2006, 1992). The ventrolateral PAG (vIPAG) contains a large population of MOR+

71 neurons, and direct administration of MOR agonists into the PAG produces potent analgesia (Satoh et al.,

72 1983; Jensen and Yaksh, 1986; Bodnar et al., 1988; Loyd et al., 2008) In addition, intra-PAG administration

73 of MOR antagonists or lesions of PAG MOR significantly attenuate the analgesic effect of systemic

74 morphine, suggesting a critical role for PAG MOR in mediating morphine action (Ma and Han, 1991; Y.

75 Zhang et al., 1998; Loyd et al., 2008).

76 We have previously shown that aged rats exhibit reduced vIPAG MOR protein expression and reduced

77 MOR agonist binding in the vIPAG compared to adult rats (Fullerton et al., 2021), suggesting that

78 diminished levels of functioning MOR in the vIPAG contribute to the attenuated opioid potency seen in the

79 aged. The present studies build on these previous findings to assess age and sex differences in MOR

80 availability, ligand affinity, phosphorylation, G-protein activation, cAMP inhibition, and expression of RGS

81 proteins. We report that aged rats, and more specifically males, exhibit reduced MOR binding potential,

82 reduced G-protein activation, reduced cAMP inhibition, and increased RGS expression compared to adults,

83 with no change in MOR phosphorylation. Similar changes were observed in females regardless of age.

84 These findings identify several mechanisms whereby opioid signaling is attenuated in the aged rat, and

85 provide a framework for the development of novel pharmacological therapies to improve pain

86 management in the elderly.

\section{$87 \quad 2$ Materials and methods}

\section{$88 \quad 2.1$ Experimental subjects}

89 Adult (2-3mos) and aged (16-18mos) male and regularly cycling female Sprague-Dawley rats were used

90 in these experiments (Charles River Laboratories, Boston, MA). Rats were co-housed in same-sex pairs

91 on a 12:12 hour light/dark cycle (lights on at 08:00 am). Access to food and water was ad libitum 
92 throughout the experiment, except during testing. All studies were approved by the Institutional Animal

93 Care and Use Committee at Georgia State University and performed in compliance with Ethical Issues of

94 the International Association for the Study of Pain and National Institutes of Health. All efforts were

95 made to reduce the number of rats used in these experiments and to minimize pain and suffering. All

96 assays were performed on separate cohorts of rats ( $n=8 /$ sex/age; $N=32$ ), with the exception of the

97 radioligand binding and GTP $\gamma$ S assays, which were run simultaneously on PAG tissue from a single

98 cohort.

\section{$99 \quad 2.2$ Vaginal cytology}

100

101

102

103

104 105 (Loyd et al., 2007).

Beginning ten days prior to testing, vaginal lavages were performed daily on adult and aged female rats to confirm that all rats were cycling regularly and to keep daily records of the stage of estrous. Proestrus was identified as a predominance of nucleated epithelial cells, and estrus was identified as a predominance of cornified epithelial cells. Diestrus 1 was differentiated from diestrus 2 by the presence of leukocytes. Rats that appeared between phases were noted as being in the more advanced stage

\subsection{CFA-induced chronic pain treatment}

10772 hours prior to experimentation, persistent inflammatory pain was induced by injection of complete

108 Freund's adjuvant (CFA; Mycobacterium tuberculosis; Sigma; 200 $\mu$ l), suspended in an oil/saline (1:1)

109 emulsion, into the plantar surface of the right hind paw. Edema was present within 24 hours of

110 injection, indicated by a $>100 \%$ change in paw diameter, determined using calibrated calipers applied

111 midpoint across the plantar surface compared to handled paw.

\section{$112 \quad 2.4$ Membrane preparation for radioligand binding and GTP $\gamma \mathrm{S}$ assays}


113 vIPAG membrane protein lysates were prepared from adult and aged, male and female, handled and

114 CFA treated rats to be used for radioligand binding and GTPYS assays. 72 hours post-CFA injection or

115 handling, rats were restrained using DecapiCones and decapitated. Brains were removed rapidly, flash-

116 frozen in 2-methyl butane on dry ice, and stored at $-80^{\circ} \mathrm{C}$. Ventrolateral PAG tissue from caudal PAG

117 (Bregma -7.5 through -8.5) was dissected from each brain using a straight edge razor at $-20^{\circ} \mathrm{C}$. On the

118 day of the assay, PAG sections were placed in ice-cold assay buffer (50 mM Tris- $\mathrm{HCl}, \mathrm{pH}$ 7.4). Tissue was

119 homogenized with a glass dounce and centrifuged at $20,000 \mathrm{~g}$ at $4^{\circ} \mathrm{C}$ for $30 \mathrm{~min}$. The supernatant was

120 discarded and the pellet resuspended in assay buffer (Li et al., 2018; Shaqura et al., 2016b, 2016a;

121 Zollner et al., 2003). Membrane protein concentration was calculated using the Bradford Assay, and

122 lysates of vIPAG membrane protein from adult and aged, male and female, naïve and CFA treated rats

$123(\mathrm{n}=4 ; \mathrm{N}=32)$ were used immediately for radioligand binding and GTP $\mathrm{S}$ assays.

\subsection{Saturation radioligand binding assay}

Saturation binding experiments were performed on vIPAG membranes using $\left[{ }^{3} \mathrm{H}\right.$ ]DAMGO (specific activity $50 \mathrm{Ci} / \mathrm{mmol}$, American Radiolabeled Chemicals, Missouri). Briefly, $100 \mu \mathrm{g}$ of membrane protein was incubated with various concentrations of $\left[{ }^{3} \mathrm{H}\right]$ DAMGO $(0.5$ to $5 \mathrm{nM})$, in a total volume of $1 \mathrm{ml}$ of binding buffer (50mM Tris- $\mathrm{HCl} \mathrm{pH}$ 7.4). Nonspecific binding was defined as radioactivity remaining bound in the presence of $10 \mu \mathrm{M}$ unlabeled naloxone. At the end of the incubation period (1h at RT) bound and free ligands were separated by rapid filtration over Whatman brand Grade GF/C glass filters

131 (Sigma-Aldrich) using a sampling vacuum manifold (MilliporeSigma). Filters were washed four times with

$1325 \mathrm{ml}$ of cold $\mathrm{dH}_{2} \mathrm{O}$. Bound radioactivity was determined by liquid scintillation spectrophotometry after overnight extraction of the filters in $3 \mathrm{ml}$ of scintillation fluid. Specific activity was calculated by subtracting the non-specific binding mean value at each concentration of $\left[{ }^{3} \mathrm{H}\right] \mathrm{DAMGO}$. All experiments

135 were performed in triplicate. $B_{\max }$ and $K_{d}$ values were determined by nonlinear regression analysis of 


\subsection{Agonist-stimulated $\left[{ }^{35} \mathrm{~S}\right] \mathrm{GTP}$ S S binding}

DAMGO-stimulated $\left[{ }^{35}\right.$ S]GTP S binding to PAG membrane protein was assessed by incubating membrane protein (100ug) in the presence or absence of $\left[{ }^{35} \mathrm{~S}\right] \mathrm{GTP} \gamma \mathrm{S}(0.1 \mathrm{nM})$ (specific activity 1250 $\mathrm{Ci} / \mathrm{mmol}$, American Radiolabeled Chemicals, Missouri) and various concentrations of DAMGO (2 to $30,000 \mathrm{nM})$ in assay buffer (20mM Tris, $10 \mathrm{mM} \mathrm{MgCl}_{2}, 100 \mathrm{mM} \mathrm{NaCl}, 0.2 \mathrm{mM}$ EGTA, pH 7.4) for 30min at $30^{\circ} \mathrm{C}$. Stimulated $\left[{ }^{35} \mathrm{~S}\right] \mathrm{GTP} \gamma \mathrm{S}$ binding was compared to unstimulated binding at each measurement point and presented as percent basal binding. At the end of the incubation period, bound and free ligands were separated by rapid filtration over Whatman brand Grade GF/B glass filters (Sigma-Aldrich) using a sampling vacuum manifold (MilliporeSigma). Filters were washed four times with $5 \mathrm{ml}$ of cold buffer (50 $\mathrm{mM}$ Tris- $\mathrm{HCl}, \mathrm{pH}$ 7.4). Bound radioactivity was determined by liquid scintillation spectrophotometry after overnight extraction of the filters in $3 \mathrm{ml}$ of scintillation fluid. All experiments were performed in duplicate. Efficacy (Emax) is defined as the maximum percent stimulation by an agonist; potency ( $\left.\mathrm{EC}_{50}\right)$ is defined as the concentration of DAMGO required for half the maximal response. Emax and $\mathrm{EC}_{50}$ values were determined by nonlinear regression analysis of concentration-effect curves using Graph Pad Prism 9.1.

\subsection{Phosphorylated MOR analysis}

To assess the impact of advanced age and sex on MOR phosphorylation state, levels of MOR phosphorylation were analyzed by Western blot. The lysis buffers used and general methods are the same as reported in (Lei et al., 2017). Briefly, rat PAG samples were homogenized in $\sim 500 \mu \mathrm{L}$ of lysis buffer using a glass dounce and rotated overnight at $4^{\circ} \mathrm{C}$. The samples were then spun down at $13,000 \mathrm{~g}$ for $10 \mathrm{~min}$ at $4^{\circ} \mathrm{C}$. The resulting lysates were quantified by DC Protein Assay Kit (Bio-Rad, \#500-0111) according to the manufacturer's instructions. $50-75 \mu \mathrm{g}$ of soluble protein per sample (same for all samples in a set) was run on 10\% Bis-Tris Bolt PAGE gels (Fisher Scientific, \#NW00100BOX), and wettransferred to nitrocellulose membrane (Protran $0.2 \mu \mathrm{m} \mathrm{NC,} \mathrm{\# 45-004-001} \mathrm{from} \mathrm{Fisher} \mathrm{Scientific)} \mathrm{at} \mathrm{30V}$ 
161

162

163

164

165

166

167

168

169

170

171

172

173

174

175

176

177

178

179

180

181

182

at $4^{\circ} \mathrm{C}$ for 2-3 hours. Membranes were blocked using 5\% nonfat dry milk in TBS, then blotted for primary antibody target in $5 \% \mathrm{BSA}$ in TBST overnight rocking at $4^{\circ} \mathrm{C}$. Primary antibodies used were: $\mathrm{pMOR}$ (1:1000, Bioss \#bs-3724R), tMOR (1 $\mu \mathrm{g} / \mathrm{mL}, \mathrm{R} \& D$ \#MAB6866), and GAPDH (1:1000, Invitrogen \#MA515738). All 3 targets were always probed for on the same blot, using low pH stripping buffer between each set. Secondary antibodies were used at 1:5000 each in 5\% nonfat dry milk in TBST, rocking for $\sim 1 \mathrm{hr}$ at room temperature. Secondary antibodies used were Goat- $\alpha$-Mouse-IRDye800CW (Fisher Scientific \#NC9401841) and Goat- $\alpha$-Mouse-IRDye680LT (Fisher Scientific \#NC0046410). Target signal was acquired using an Azure Sapphire imager using the near-infrared channels (658 and $784 \mathrm{~nm}$ ). Band density was quantified, and background subtracted using the onboard AzureSpot analysis software. Samples were run with at least two representatives of each experimental group on the same gel. Adult and aged, male and female, naïve and CFA treated rats $(n=4 ; N=32)$ were used for these experiments. pMOR signal was normalized to the same sample tMOR or GAPDH as indicated, and all samples were normalized to the Adult Male average on each gel before combining data from different gels.

\subsection{Agonist-dependent cAMP inhibition}

DAMGO-dependent cAMP inhibition was analyzed using a cAMP assay. vIPAG membrane protein lysates were prepared from adult and aged, male and female, handled and CFA treated rats. 72 hours post-CFA injection or handling, rats were restrained using DecapiCones and decapitated. Brains were removed rapidly, flash-frozen in 2-methyl butane on dry ice, and stored at $-80^{\circ} \mathrm{C}$. Ventrolateral PAG tissue from caudal PAG (Bregma -7.5 through -8.5) was dissected from each brain using a straight edge razor at $20^{\circ} \mathrm{C}$. Briefly, vIPAG tissues were homogenized in ice-cold lysis buffer containing $0.25-\mathrm{M}$ sucrose, $50-\mathrm{mM}$ Tris-HCl pH 7.5, 5-mM EGTA, 5-mM EDTA, 1-mM phenylmethylsulfonyl fluoride, 0.1-mM dithiothreitol, and $10 \mu \mathrm{g} / \mathrm{ml}$ leupeptin. The homogenized tissues were then centrifuged at $1000 \times \mathrm{g}$ for $5 \mathrm{~min}\left(4^{\circ} \mathrm{C}\right)$ and the supernatant was centrifuged at $35000 \times g$ for 10 min (Viganò et al., 2003). vIPAG membrane protein 
samples (100ug) from adult and aged, male and female, naïve and CFA treated rats ( $n=4 ; N=32$ ) were

incubated in 1uM forskolin (FSK) and in the presence or absence of 10uM DAMGO to stimulate adenylate cyclase activity. cAMP levels in vIPAG tissue were determined using the LANCE Ultra cAMP immunoassay. Data are plotted as \% change in TR-FRET signal comparing FSK baseline measurements to measurements following DAMGO-stimulated cAMP inhibition.

\subsection{Single-molecule fluorescence in situ hybridization}

192 Single-molecule fluorescent in situ hybridization (RNAscope) assays were used to determine mRNA expression of OPRM1, RGS9-2, and RGS4 in the vIPAG. Rats were restrained using DecapiCones and

194 decapitated. Brains were removed rapidly, flash frozen in 2-methyl butane on dry ice, and stored RNase free at $-80^{\circ} \mathrm{C}$. Frozen tissue was sectioned in a $1: 6$ series of $20 \mu \mathrm{m}$ coronal sections at $-20^{\circ} \mathrm{C}$ with a

197 at $-80{ }^{\circ} \mathrm{C}$ until the time of the assay. vIPAG sections from adult and aged, male and female, naïve and morphine treated rats were used $(n=4 ; N=32)$. For morphine dosing paradigm see (Fullerton et al., the RNAscope Multiplex Kit protocol (Advanced Cell Diagnostics) using probes for OPRM1, RGS4, and RGS9-2. To facilitate cellular mRNA quantification within the vIPAG, sections were counterstained with DAPI. mRNA puncta were visualized as fluorescent signal. Fluorescent images were captured on Zeiss LSM 700 Confocal Microscope at 40x, and mRNA expression (target puncta/DAPI) was calculated using

204 Imaris software. To determine RGS4 and RGS9-2 expression levels in MOR+ neurons, quantification was restricted to puncta located within $10 \mu \mathrm{m}$ of DAPI that co-expressed OPRM1 mRNA. mRNA expression representative levels of the mid-caudal PAG (Bregma -7.74 and -8.00). As there was no significant effect 
each rat. RGS4 and RGS9-2 mRNA values are expressed as the mean \pm standard error of the mean (SEM).

All images were collected and analyzed by an experimenter blinded to the experimental condition.

\subsection{Statistical analysis and data presentation}

212 All values are reported as mean \pm SEM. Data were assessed for normality and homogeneity of variance

213 using Shapiro-Wilk and Bartlett's tests. Significant main effects of sex, age, and treatment were assessed

214 using ANOVA; $p<0.05$ was considered statistically significant. Tukey's post-hoc tests were conducted to 215 determine significant mean differences between groups that were a priori specified. Data are expressed 216 either as fmol/protein or nM DAMGO for radioligand binding assay, or Emax or EC50 for GTPyS assay.

\section{$217 \quad 3$ Results}

\subsection{Advanced age and sex impact vIPAG MOR binding properties}

219 To assess the impact of advanced age, biological sex, and pain on vIPAG MOR signaling, we first used radioligand saturation binding assays to determine MOR binding parameters. The saturation binding

221 curves generated with $\left[{ }^{3} \mathrm{H}\right] \mathrm{DAMGO}$ are shown in Fig. 1A. There was no significant impact of CFA

222 treatment on any measures, so CFA and handled groups were combined.

Kd values, indicative of receptor affinity, were determined using the concentration-effect curves

224 generated from each sample. Analysis of $\mathrm{Kd}$ values indicated no significant impact of age $\left[\mathrm{F}_{(1,26)}=0.770\right.$,

$225 p=0.388]$ or sex $\left[F_{(1,26)}=1.241, p=0.275\right]$, or a significant interaction $\left[F_{(1,26)}=1.278, p=0.269\right]$ (Fig. 1B).

226 Analyses of $B_{\max }$ values, indicative of receptor availability, showed no significant impact of age $\left[\mathrm{F}_{(1,28)}=\right.$

$2272.661, p=0.114]$ or $\operatorname{sex}\left[F_{(1,28)}=0.002, p=0.967\right]$, but a significant interaction $\left[F_{(1,28)}=4.995, p=0.034\right]$. Post

228 hoc analysis showed a significant difference in vIPAG MOR availability between adult males and aged

229 males, as evidenced by reduced $B_{\max }$ values in the aged males compared to their adult counterparts $(p=$ 
231 females and aged females exhibited smaller reductions in $\mathrm{B}_{\max }$ compared to their adult male

232 counterparts (\% $\Delta-23.6$ and -17.1 , respectively. Fig. 1C).

233 Analyses of binding potential (BP) values, a measure that takes into consideration the density of

234 available receptors and the affinity of the receptor for its agonist, showed a significant impact of sex,

235 with males exhibiting greater binding potential than females $\left[F_{(1,28)}=4.631, p=0.040\right]$ and a significant

236 interaction between age and $\operatorname{sex}\left[F_{(1,28)}=9.110, p=0.005\right]$. No significant impact of age $\left[F_{(1,28)}=3.312\right.$,

$237 p=0.079]$ was observed. Post hoc analyses showed a significant difference in vIPAG MOR binding

238 potential between adult males and adult females $(p=0.006)$, and adult males and aged males $(p=$

$2390.010)$, indicating that adult males exhibit greater vIPAG MOR binding potential than their aged male

240 counterparts and their adult female counterparts (Fig. 1D). Adult females, aged males, and aged females

241 all exhibited marked reductions in MOR binding potential compared to their adult male counterparts

$242(\% \Delta-52,-48.7$, and -40 , respectively; Fig. 1D). 

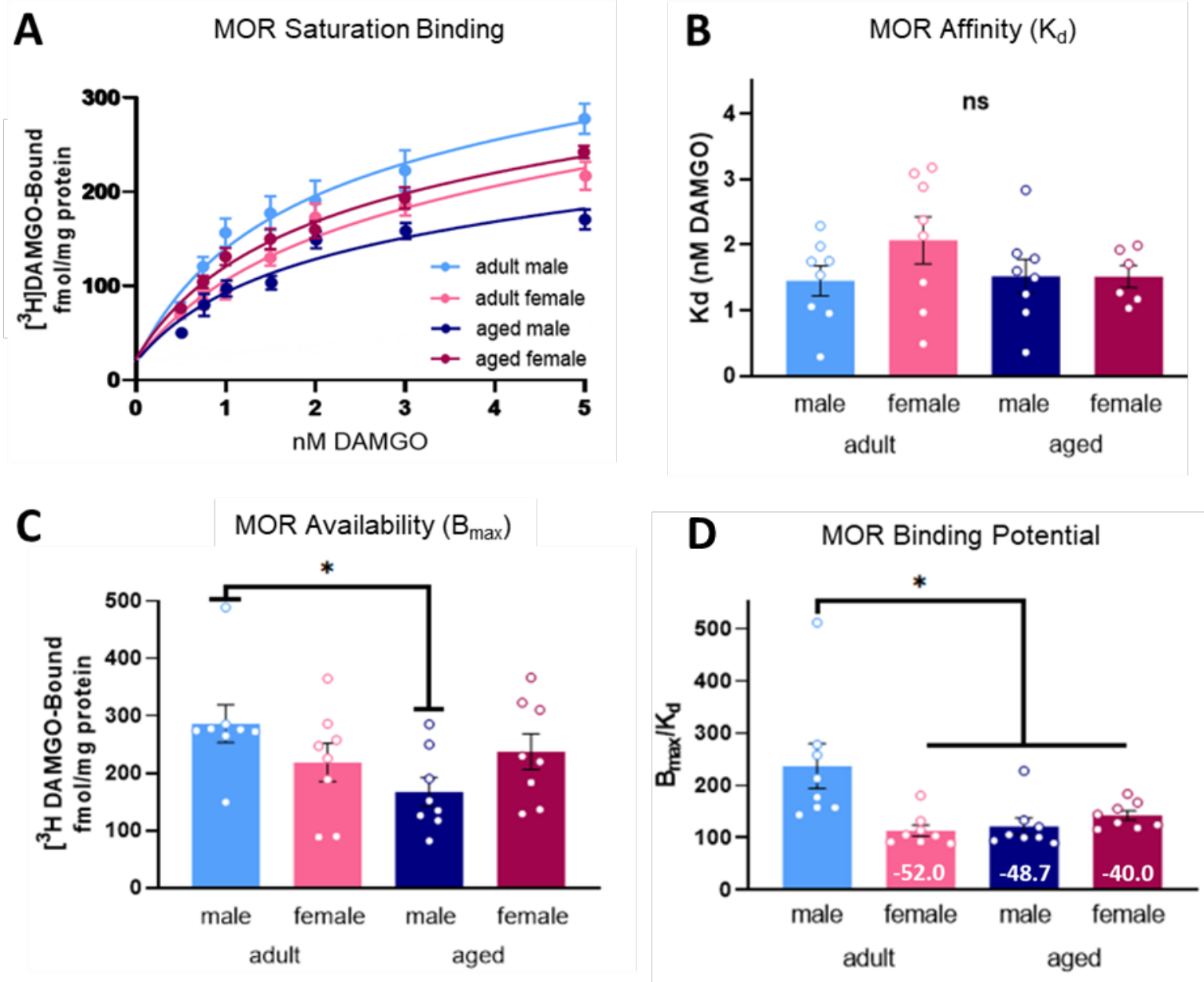

Fig. 1. Saturation binding curve of bound [3H]DAMGO (A). No significant effect of age or sex was observed in MOR affinity $\left(K_{d}\right)(B)$. MOR availability $\left(B_{\max }\right)$ was significantly lower in aged males compared to adult males (C). Adult females, aged males, and aged females exhibited reduced MOR binding potential $\left(\mathrm{B}_{\max } / \mathrm{K}_{\mathrm{d}}\right)$ compared to adult males, indicating attenuated agonist interaction at the receptor level (D). ns, not significant. *Significant difference between adult and aged males, or adult males and adult females; $p<0.05$ calculated by Tukey's post hoc test. Graphs indicate mean \pm SEM. Values indicate $\%$ change from adult male.

\subsection{Advanced age and sex impact opioid-induced G-protein activation in the vIPAG} mediated G-protein activation. Preliminary studies revealed a significant main effect of chronic pain $\left[F_{(1,}\right.$ $\left.{ }_{23}=21.16, p=0.0001\right]$. To improve the translatability of these results to the target population of aged patients suffering from chronic pain, GTPyS experiments were performed exclusively on CFA-treated 
rats. Concentration curves generated from $\left[{ }^{35} \mathrm{~S}\right] \mathrm{GTP} \gamma \mathrm{S}$ assays are shown in Fig. $2 \mathrm{~A}$. Analyses of $\mathrm{E}_{\max }$ values, a measure of G-protein availability combined with ligand efficacy, indicated no significant impact of age $\left[\mathrm{F}_{(1,24)}=0.035, \mathrm{p}=0.8532\right]$ or $\operatorname{sex}\left[\mathrm{F}_{(1,25)}=2.852, \mathrm{p}=0.1042\right]$, or a significant interaction $\left[\mathrm{F}_{(1,24)}=\right.$ 2.023, $p=0.1678]$ (Fig. 2B).

Analyses of $\mathrm{EC}_{50}$ values, a measure of the concentration of DAMGO required for half-maximal G-protein binding, indicated a significant impact of sex, with males exhibiting lower effective concentration values than females, reflecting a higher potency of activation $\left[F_{(1,24)}=5.177, p=0.0321\right]$. There was no significant impact of age $\left[F_{(1,24)}=2.339, p=0.1393\right]$, and no significant interaction $\left[F_{(1,24)}=2.473, p=\right.$ 0.1289] (Fig. 2C). Compared to their adult male counterparts, aged males, adult females, and aged females all exhibited marked increases in $\mathrm{G}$-protein $\mathrm{EC}_{50}$ as evidenced by their percent change values (\% $\Delta 60.5,114.8$, and 98.6 , respectively), reflecting a lower potency of activation (Fig. 2C). Together, these results suggest that opioid-induced G-protein signaling is impaired in the PAG of the aged rat and the female rat.

Next, we calculated the coefficient ratio of analysis of $\mathrm{E}_{\max } / \mathrm{EC}_{50}$, which is indicative of overall G-protein activation efficiency. A significant impact of age was noted, with adults exhibiting higher vIPAG Gprotein activation efficiency than aged rats $\left[F_{(1,24)}=6.491, p=0.0177\right]$. There was also a significant impact of sex, with males exhibiting higher vIPAG G-protein activation efficiency compared to females $\left[F_{(1,24)}=10.39, p=0.0036\right]$. A significant interaction was also observed $\left[F_{(1,24)}=13.93, p=0.0010\right]$. Post hoc analyses showed a significant difference in vIPAG G-protein activation efficiency between adult males and aged males $(p=0.0009)$, with adult males exhibiting greater vIPAG G-protein activation efficiency than aged males. A significant difference in vIPAG G-protein activation efficiency between adult males and adult females ( $p=0.0003$ ) was also observed, with adult males exhibiting greater vIPAG G-protein activation efficiency than adult females (Fig. 2D). Aged males, adult females, and aged females 


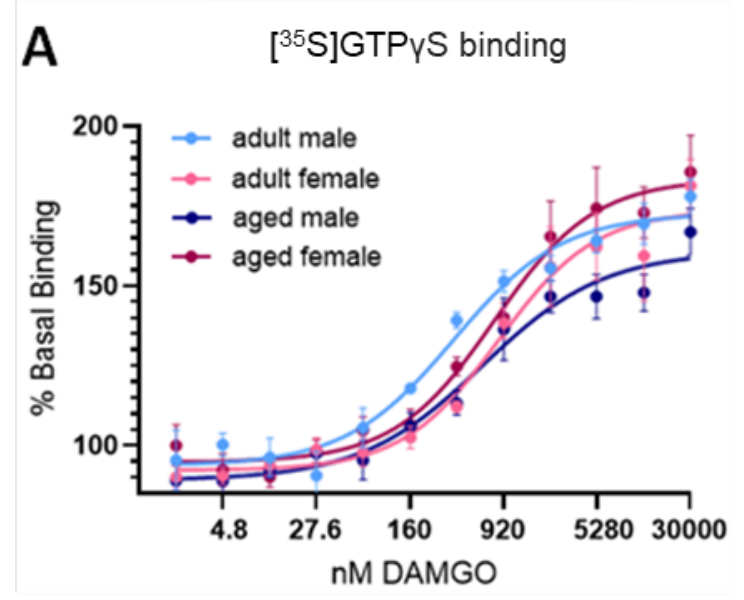

B G-protein efficacy $\left(E_{\max }\right)$
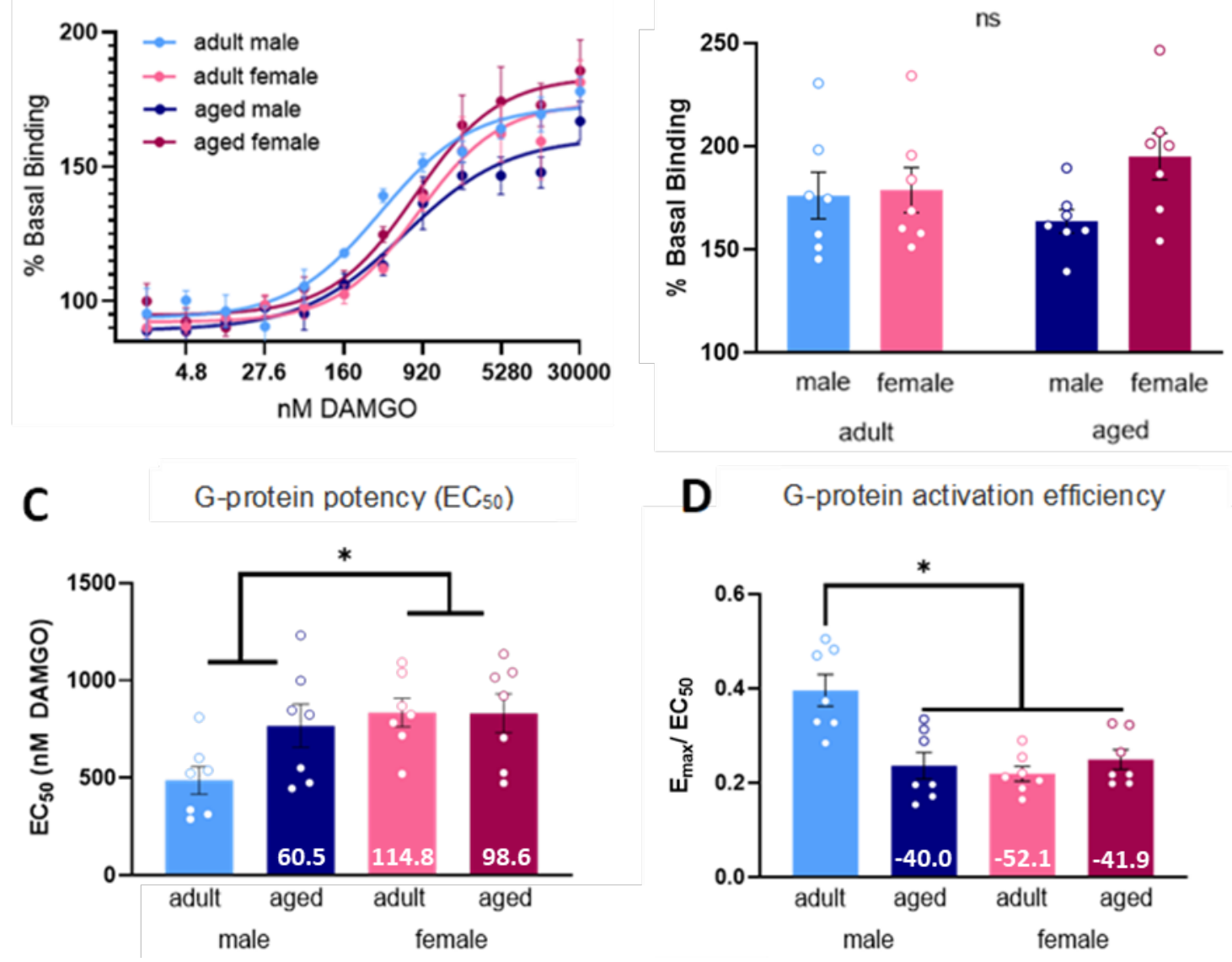

282

283

284

285

286

287

288

289

Fig 2. $\left[{ }^{35} \mathrm{~S}\right] \mathrm{GTP} \gamma \mathrm{S}$ binding curve of agonist-stimulated GTP $\gamma \mathrm{S}$ binding (A). No significant effect of age or sex was observed in $\mathrm{E}_{\max }(\mathrm{B})$. Aged males, adult females, and aged females exhibited increased $\mathrm{EC}_{50}$ values compared to adult males, indicating that adult males have the greatest potency (C). Aged males, adult females, and aged females exhibited reduced G-protein activation efficiency $\left(E_{\max } / E_{50}\right)$ compared to adult males, indicating attenuated G-protein signaling (D). ns, not significant. *Significant difference between adult and aged males, or adult males and adult females; $p<0.05$ calculated by Tukey's post hoc test. Graphs indicate mean \pm SEM. Values indicate $\%$ change from adult male. 


\subsection{Advanced age and sex do not impact phosphorylated MOR in the vIPAG}

293

294

295

296

297

298

299

300

301

The results above showed significant reductions in MOR binding potential and G-protein activation efficacy. Therefore, we next examined if there was an effect of age and sex on MOR phosphorylation, as increased levels of pMOR would likely contribute to these reductions. Western blots were used to determine the impact of advanced age on MOR phosphorylation at serine-375, a known site of phosphorylation-mediated desensitization (Schulz et al., 2004). There was no significant impact of treatment, so CFA and handled groups were combined. Although increased pMOR/tMOR was observed in aged males compared to their adult counterparts $(\% \Delta 34.0)$, no significant main effect of age $\left[\mathrm{F}_{(1,41)}=\right.$ 2.168, $p=0.1486]$, sex $\left[F_{(1,41)}=1.807, p=0.1863\right]$, or age $x$ sex interaction $\left[F_{(1,41)}=0.4615, p=0.5008\right]$ was observed (Fig. 3).

\section{Phosphorylated MOR}

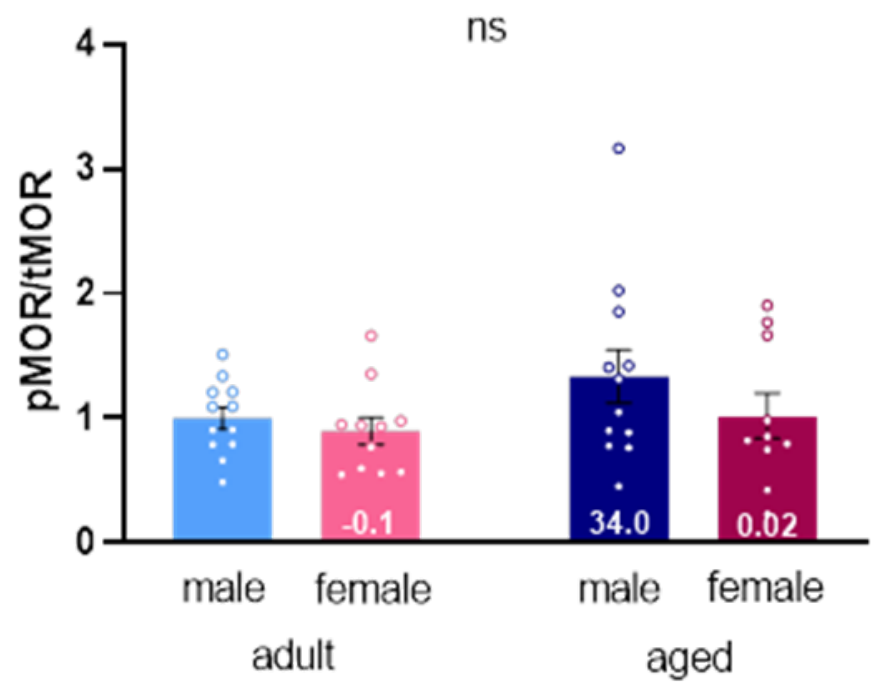

Fig 3. No significant impact of advanced age or biological sex on the ratio of phosphorylated MOR/ total 304 MOR. ns, not significant. Graph indicates mean \pm SEM. Values indicate $\%$ change from adult male. 


\subsection{Advanced age and sex impact opioid-induced cAMP inhibition in the vIPAG}

We next determined if advanced age, biological sex, or persistent pain impacted opioid-induced cAMP inhibition in the vIPAG. Forskolin-induced cAMP release was used as a baseline measurement for each group, while forskolin + DAMGO was used to assess the degree to which cAMP was inhibited by DAMGO. Percent change from baseline was used to compare across treatment groups (Fig. 4A). There

312 was no significant impact of persistent pain on any measures, so CFA and handled groups were

313 combined. Our analyses revealed a significant main effect of age $\left[F_{(1,30)}=9.314, p=0.0047\right]$, a significant

314 main effect of $\operatorname{sex}\left[\mathrm{F}_{(1,30)}=10.31, \mathrm{p}=0.0031\right]$, and a significant interaction $\left[\mathrm{F}_{(1,30)}=14.24, \mathrm{p}=0.0007\right]$.

315 Post hoc analyses showed a significant difference in CAMP inhibition between adult males and adult

316 females $(p=0.0002)$, adult males and aged males $(p=0.002)$, and adult males and aged females $(p=$

317 0.004), indicating that DAMGO elicits greater cAMP inhibition in adult males compared to aged males

318 and females (both adult and aged) (Fig. 4B). 


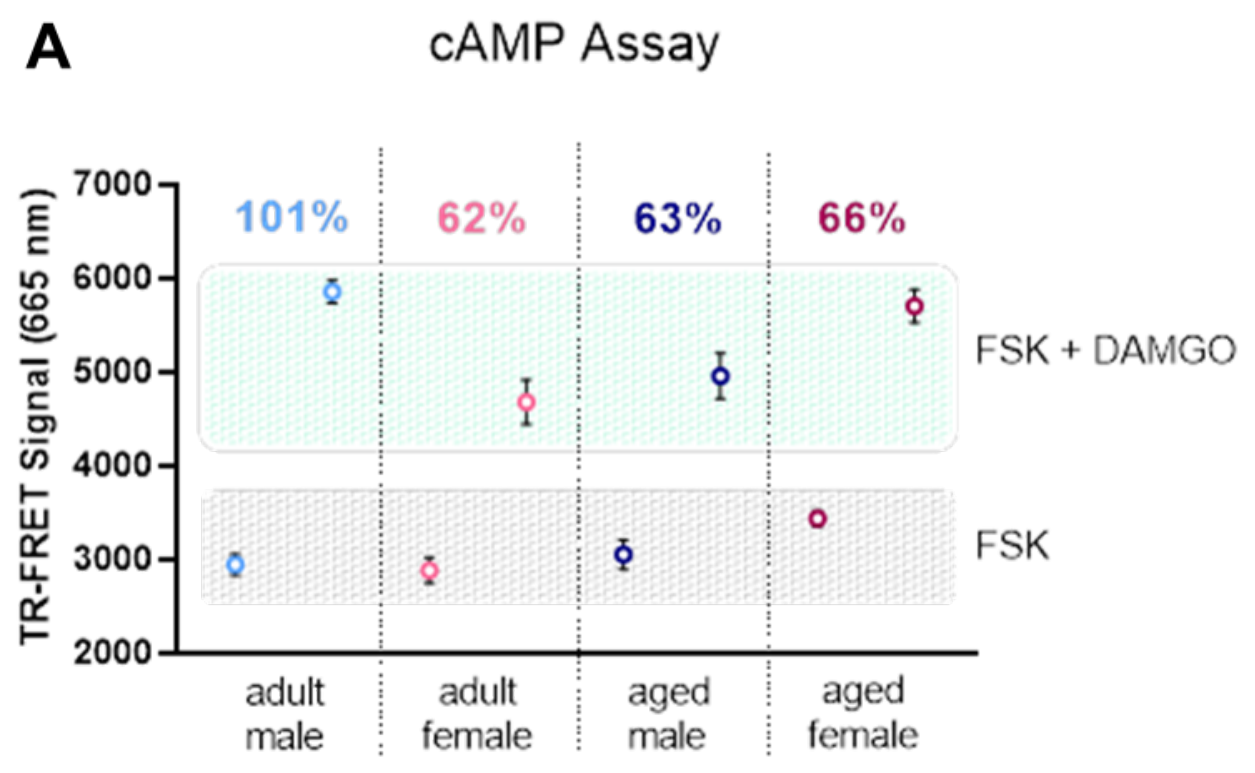

\section{B Agonist-dependent cAMP inhibition}

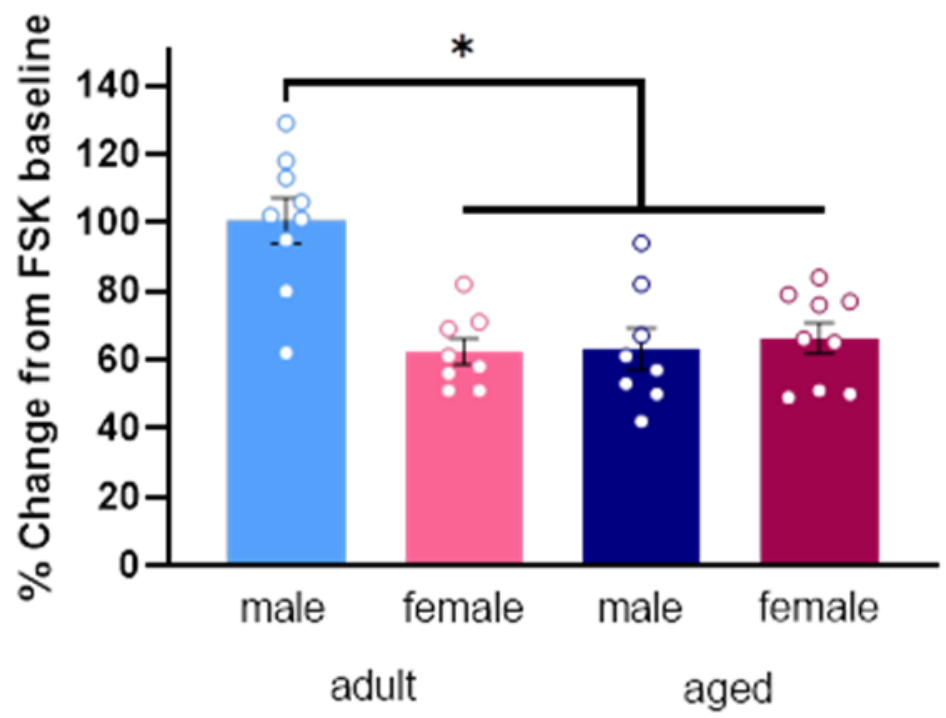

Fig 4. TR-FRET immunoassay showing $\%$ change from FSK stimulated baseline and DAMGO inhibited cAMP (cAMP levels are inversely proportional to TR-FRET signal). Adult males exhibited the highest level of agonist-dependent \% change in CAMP (A). Aged males and females exhibited reduced agonistdependent CAMP inhibition compared to adult males, indicating attenuated downstream opioid signaling (B). *Significant difference between adult and aged males, or adult males and adult females; $\mathrm{p}<0.05$ calculated by Tukey's post hoc test. Graphs indicate mean \pm SEM. Values indicate $\%$ change from FSK baseline. 


\subsection{Advanced age and sex impact RGS4 and RGS9-2 expression in the vIPAG}

329

330

331

332

333

334

335

336

337

338

339

340

341

342

343

344

345

346

347

348

Regulator of G-protein Signaling (RGS) proteins act as GAP accelerators to negatively modulate Gprotein signaling. RGS protein family members RGS4 and RGS9-2 are expressed in the VIPAG and have both been shown to regulate opioid signaling by reversing G-protein activation. Therefore, we next used smFISH to determine if RGS4 and RGS9-2 expression in the vIPAG was altered by advanced age and biological sex. In these studies, following CFA administration, a cohort of rats was administered morphine to examine the relationship between morphine $\mathrm{EC}_{50}$ and $\mathrm{RGS}$ levels. However, no differences were noted between the morphine and naive conditions, so these groups were combined. First, we assessed total vIPAG expression of RGS4 and RGS9-2. These analyses revealed a significant main effect of age on both RGS4 $\left[F_{(1,37)}=18.15, p=0.0001\right]$ and RGS9-2 $\left[F_{(1,41)}=17.09, p<0.0002\right]$, with aged rats exhibiting increased levels of RGS4 and RGS9-2 mRNA compared to their adult counterparts (Fig. 5A \& B). No significant main effect of sex on RGS4 $\left[F_{(1,37)}=0.0247, p=0.8763\right]$ or RGS9-2 $\left[F_{(1,41)}=0.4855, p=\right.$ 0.4903], or significant interactions between age and sex for $\operatorname{RGS4}\left[F_{(1,37)}=0.4994, p=0.4842\right]$ or $R G S 9-2$ $\left[F_{(1,41)}=0.3246, p=0.5723\right]$ were observed (Fig. 5A \& B).

Following our assessment of total RGS4 and RGS9-2, we next restricted our analyses to RGS4 and RGS9-2 mRNA expressed on MOR+ neurons. Similar to what was noted above, a significant main effect of age on expression of RGS4 $\left[F_{(1,41)}=26.47, p<0.0001\right]$ and RGS9-2 $\left[F_{(1,41)}=21.69, p<0.0001\right]$ was observed, with aged rats exhibiting increased levels of RGS4 and RGS9-2 mRNA in MOR+ neurons compared to their adult counterparts (Fig. 5C \& D). No main effect of sex for RGS4 $\left[F_{(1,41)}=0.7881, p=0.3799\right]$ or RGS9-2 $\left[F_{(1,41)}=0.0006, p=0.9799\right]$, or significant interactions between age and sex for $\operatorname{RGS4}\left[F_{(1,41)}=0.6583, p=\right.$ 0.4219] or RGS9-2 [F(1,41) $=0.0075, p=0.9314]$ were observed (Fig. 5C \& D). 
A VIPAG RGS4 expression

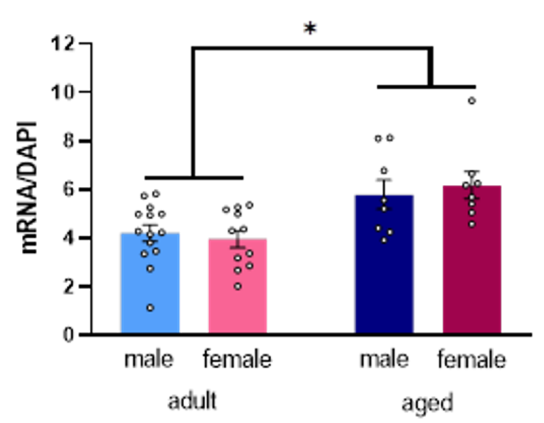

C MOR+RGS4 expression

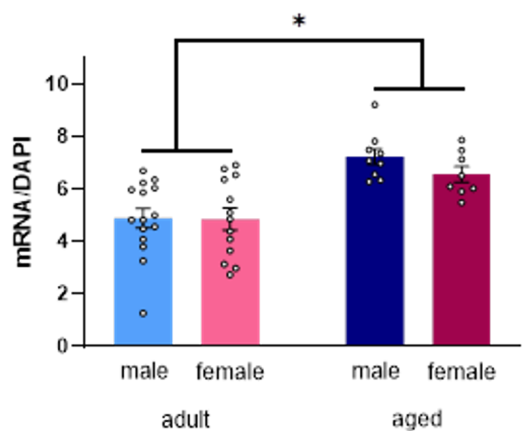

adult

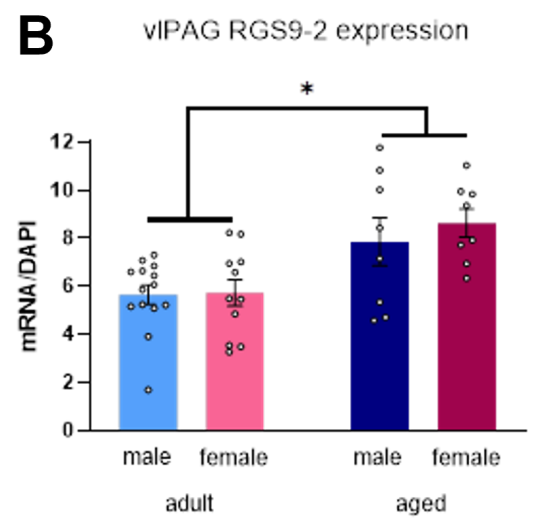

D MOR+RGS9-2 expression

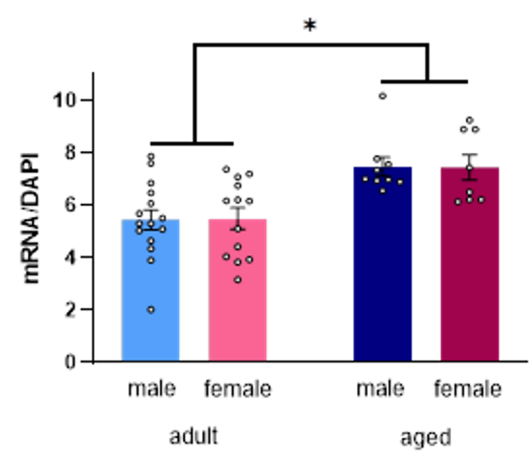

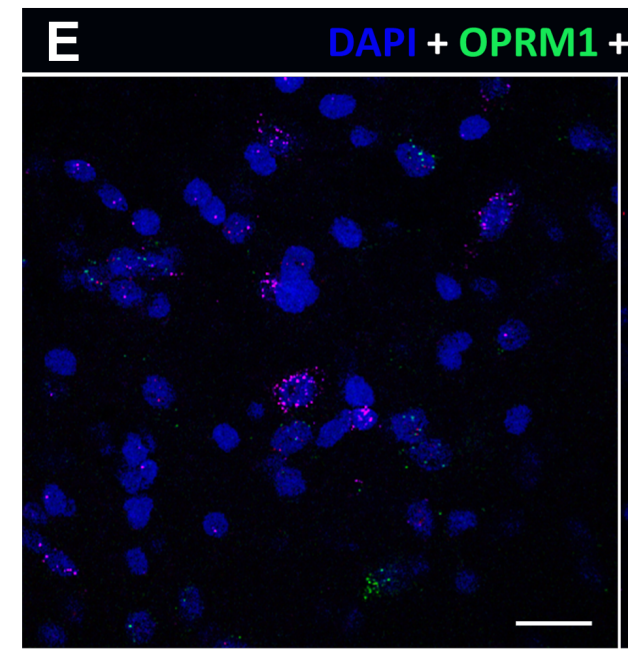

adult male $\underline{20 \mu \mathrm{m}}$

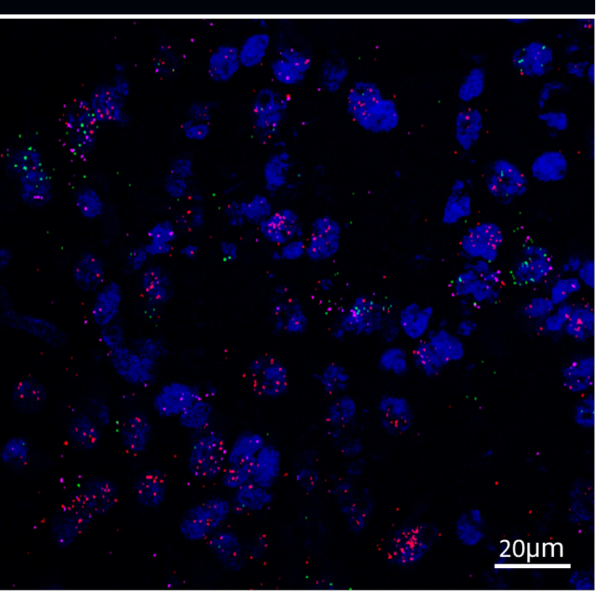

aged male

Fig 5. mRNA expression of RGS4 (A) and RGS9-2 (B) in the vIPAG was significantly greater in aged rats compared to adults. mRNA expression of RGS4 (C) and RGS9-2 (D) on MOR+ cells in the vIPAG was significantly greater in aged rats compared to adults. (E) Photomicrograph of RGS expression compared an adult male and an aged male PAG section. *Significant difference between adults and aged rats; $p<0.05$ calculated by $2 \times 2$ ANOVA. Graphs indicate mean \pm SEM. 


\section{Discussion}

The present studies are the first to show that advanced age results in a significant attenuation in MOR signaling within the vIPAG of male and female rats. Specifically, aged males and females (regardless of age) showed decreased MOR binding potential, decreased G-protein activation, and decreased agoniststimulated cAMP inhibition in comparison to adult males (Fig. 6). These changes, along with the observed increase in RGS4 and RGS9-2 expression, provide a mechanism whereby morphine potency is significantly reduced in aged rats (Fullerton et al., 2021). These changes also support our earlier observed sex difference whereby adult females have a lower opioid analgesic potency than adult males, equivalent to aged males and females.

Age-induced changes in PAG MOR signaling

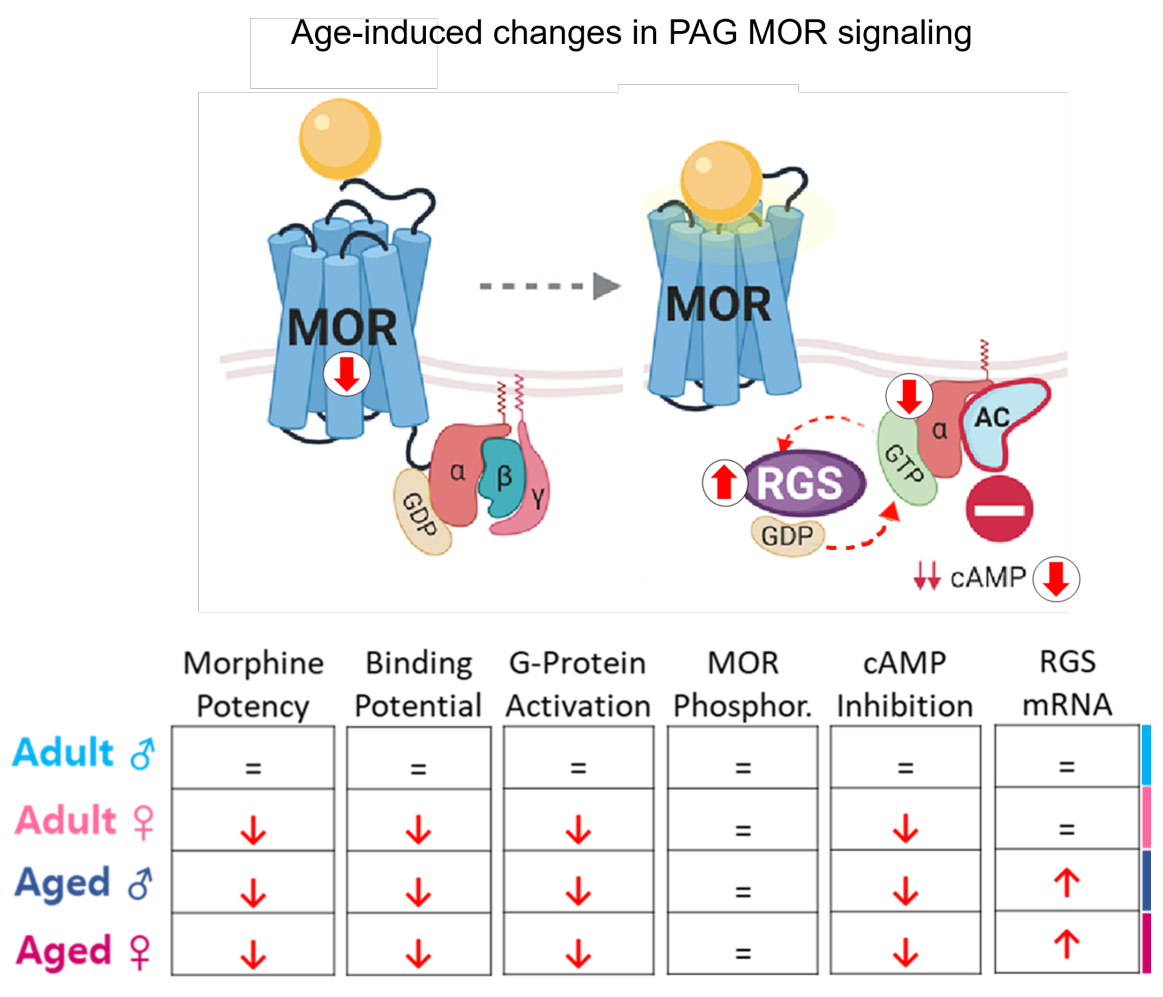

Fig 6. Model and table of MOR signaling impairments in the vIPAG of the aged and female rat. Aged and female rats exhibit decreased MOR binding potential, decreased G-protein activation, and decreased cAMP inhibition, while aged rats alone demonstrate increased RGS expression. No impact of age or sex was found in phosphorylation of MOR at serine-375. 
374 In our previous study, we reported that morphine potency to block persistent inflammatory pain is 375 reduced in aged and female rats, likely due to a reduction in DAMGO binding in the vIPAG (Fullerton et 376 al., 2021). Consistent with that finding, we report here that the vIPAG MOR binding potential in aged 377 males and females of either age is significantly reduced in comparison to adult male rats, providing 378 additional support that the decrease in opioid potency observed in these groups is driven, in part, by 379 reduced expression/availability of MOR in the vIPAG. Notably, we did not observe an impact of advanced age or sex on the MOR's affinity for its ligand, as there were no significant effects of age or sex on DAMGO $K_{d}$ values. However, aged males had reduced MOR availability as evidenced by lower $B_{\max }$ values compared to their adult male counterparts. This result is consistent with our previous finding that aged males exhibited reduced DAMGO binding in the vIPAG (assessed using autoradiography) (Fullerton et al., 2021), and together, suggest an age-induced downregulation of PAG MOR in males matching a consistently lower level of MOR expression in females of any age. This apparent decrease in MOR expression may explain the reduced analgesic potency of morphine in females and aged males in our earlier work (Fullerton et al., 2021).

Here we report no impact of persistent inflammatory pain on vIPAG MOR binding potential, consistent with previous preclinical and clinical studies assessing the impact of chronic pain on MOR binding in the CNS. For example, patients with chronic fibromyalgia pain exhibit no changes in MOR binding in the PAG, despite having significant reductions in several brain regions, including the nucleus accumbens and the amygdala (Harris et al., 2007). Similarly, no change in PAG MOR binding was noted as a result of peripherally localized chronic pain generated from proximal nerve injury (Maarrawi et al., 2007). Interestingly, centrally localized neuropathic pain (generated from supraspinal injury) was associated 395 with a significant reduction of PAG MOR binding, suggesting that the origin of chronic pain within the CNS is critical in promoting alterations in neural MOR signaling (Maarrawi et al., 2007). Preclinical 
studies in rodents also suggest that changes in MOR induced by persistent pain are CNS site-specific. For example, persistent inflammatory pain induced by intraplantar CFA increased MOR binding in the dorsal root ganglion at 24 and 96 hours post-CFA, (Mousa et al., 2001; Zollner et al., 2003), with no change in MOR noted for the hypothalamus or spinal cord (Shaqura et al., 2004). Similarly, no change in PAG MOR availability or expression was observed following sciatic nerve injury, although reductions were noted for the insula, caudate putamen, and motor cortex (Thompson et al., 2018). Taken together, these results suggest that chronic pain alters MOR signaling in a CNS region-specific manner that is dependent on the site and modality of the pain.

\section{Impact of advanced age and sex on G-protein activation}

Agonist binding at MOR activates Gai/o -proteins and downstream signaling cascades which are critical for opioid-mediated hyperpolarization (Laugwitz et al., 1993; Connor and Christie, 1999; Koehl et al., 2018). In the present study, we found that adult males exhibit greater G-protein activation efficiency compared to aged males and adult and aged females, suggesting that the decreases in opioid potency observed in the aged males and the females are driven, in part, by attenuated G-protein-MOR coupling

411 in the vIPAG. A significant impact of biological sex on G-protein potency $\left(\mathrm{EC}_{50}\right)$ was also observed, with

412 females and aged males showing a reduction in the potency of opioid-dependent G-protein activation,

413 as evidenced by increased $\mathrm{EC}_{50}$ values. This reduction in vIPAG G-protein activation likely contributes to

414 previous studies reporting that females are less sensitive to the analgesic effects of opioids (Kest et al.,

415 2000; Loyd et al., 2008; Wang et al., 2014; Fullerton et al., 2018). Although the mechanism by which this

416 change in potency occurs is not known, the nature of the GTP $\gamma$ S assay is suggestive. The assay uses

417 membrane preparations without soluble signaling regulators like kinases present. Similarly, the GTPYS

418 molecule itself is not hydrolyzable, and is thus not subject to regulation by GAPs like the RGS proteins.

419 Considering these factors, the observed decrease in G protein activation potency may be due to the 420 observed decrease in opioid receptor expression/availability in the binding studies above. 
422 Interestingly, this was the only assay where an impact of persistent inflammatory pain was observed.

423 Specifically, CFA treated rats had reduced $\mathrm{EC}_{50}$ values, regardless of age or sex. Reductions in Ga subunit

424 expression have also been reported within both the rostral ventromedial medulla and spinal cord dorsal

425 horn following intraplantar CFA in adult male rats (Wattiez et al., 2017). The mechanism whereby

426 persistent inflammatory pain would impact G-protein activation, and not the other pharmacodynamics

427 of MOR, is not known. Also unknown are the mechanisms by which advanced age and sex alter G-

428 protein-MOR signaling. Previous studies have reported that advanced age results in a global

429 downregulation of Gai/o, most notably in the prefrontal cortex (Young et al., 1991; Alemany et al., 2007;

430 de Oliveira et al., 2019), that is not associated with overall cell loss. Indeed, the Gai/o subunit in

431 particular appears to be highly susceptible to the aging process, with estimates of reduced expression as

432 high as 65\% in the frontal cortex, hippocampus, substantia nigra, and striatum (de Oliveira et al., 2019).

433 Although age-induced changes in Gai/o expression were not assessed specifically in PAG, a widespread

434 reduction in Gai/o as a function of advanced age would likely impact the PAG, thereby limiting MOR-G-

435 protein coupling and reducing both G-protein activation efficiency and opioid potency in the aged rat.

436 Alternatively, an uncoupling between MOR and Gai/o and/or a switch in Ga subunit from Gai/o to Gas

437 cannot be ruled out (Gintzler and Chakrabarti, 2000, 2004, 2006). Indeed, a shift from Gai/o to Gas

438 would similarly increase adenylate cyclase activity, resulting in reduced hyperpolarization and decreased

439 morphine potency. Clearly, additional studies assessing the impact of advanced age on the expression of

440 Ga isoforms are warranted (Lamberts et al., 2011).

441 The present studies used the high-affinity MOR agonist DAMGO for both the radioligand binding and

442 GTPyS assay. As previous studies have reported that the pharmacodynamics of MOR may be agonist-

443 dependent, this possibility cannot be ruled out and future studies should consider incorporating at least

444 two agonists in all assays. Alternatively, a contribution by OPRM1 splice variants induced as a function of 
age may also be present (Pan et al., 2005; Alvarez et al., 2002; Narayan et al., 2021). Indeed, specific

446 alternative MOR isoforms are known to promote ligand-dependent regulation of opioid signaling

447 (Pasternak et al., 2004; Oldfield et al., 2008). MOR-1B, a family of MOR isoforms expressed in the brain,

448 are indistinguishable from MOR-1 at the extracellular surface and the agonist binding pocket but elicit

449 alternative signaling properties that impact opioid-induced cell hyperpolarization, and dysregulation of

450 these MOR splice variants has been implicated in advanced age (Latorre and Harries, 2017; Li et al.,

451 2017; Wang et al., 2018). There are also reports of sex differences in the expression of MOR splice

452 variants in the PAG, with male rodents expressing higher levels of MOR-1B5, and females expressing

453 higher levels of MOR-1B1 and MOR-1B2 (Liu et al., 2018). The unique conformation of MOR isoforms

454 and subsequent alterations in receptor phosphorylation would directly influence the G-proteins to

455 which MORs couple, potentially resulting in biased agonism (Verzillo et al., 2014; Abrimian et al., 2021).

\section{Impact of advanced age and sex on MOR Phosphorylation}

457 The results of the radioligand binding and GTPYS assays suggested that aged and female rats exhibit 458 decreased receptor expression and activation potency. It has been previously shown that MOR can be desensitized by phosphorylation in its basal state, thereby limiting agonist activation (Zhang et al., 1996;

460 Yu et al., 1997; Groer et al., 2011). Thus, we tested the hypothesis that the observed reductions in G-

461 protein activation efficiency were due to age- and sex-induced changes in basal MOR phosphorylation.

462 Although aged rats expressed higher levels of MOR phosphorylation at serine-375 compared to the 463 adults, this result was not significant, suggesting that the reductions in activation potency observed in

464 the vIPAG of aged and female rats is likely driven by an alternative mechanism. 
impact of advanced age or sex on GRK-mediated MOR phosphorylation, MOR signaling is also

471 (GAIP), an RGS protein that acts as a GTPase activator to reduce opioid signaling at the level of G-protein

472 activation (Ogier-Denis et al., 2000). Indeed, pharmacological inhibition of ERK1/2 phosphorylation in a

473 rat model leads to improved morphine analgesia (Popiolek-Barczyk et al., 2014; Melkes et al., 2020).

474 Thus, the age- and sex-induced changes in morphine potency may be driven in part by age-induced

475 hyper-phosphorylation of ERK1/2 and result in the downregulation of G-protein signaling.

\section{Impact of advanced age and sex on cAMP inhibition}

477

478

479

Agonist binding at MOR elicits a conformational change in the receptor that allows the G-protein $\alpha$ and $\beta \gamma$ subunits to interact with downstream effectors. Notably, the Ga subunit binds to adenylate cyclase (AC) and inhibits the conversion of adenosine triphosphate (ATP) to CAMP, thus limiting the activation of CAMP-dependent protein kinase (PKA) and ultimately inducing higher levels of hyperpolarization (Christie, 2008; Santhappan et al., 2015). In the present study, aged males and adult and aged females exhibited significantly lower levels of DAMGO-induced cAMP inhibition compared to adult males, suggesting an attenuated activity of the $\alpha$ subunit at the level of AC, or a weakened relationship between AC and CAMP. This effect could easily be due to the observed decreases in MOR expression and activation potency observed above. This attenuated CAMP inhibition in the aged and female rats likely contributes to the observed reduction in opioid potency and may also be due, in part, to decreased basal CAMP levels in the aged brain. Reductions in cAMP have been reported in several rodent brain regions including the cortex, thalamus, hypothalamus, and midbrain (Puri and Volicer, 1981; Titus et al., 2013; Kelly, 2018). Additional evidence suggests that aged rodents elicit widespread reductions in ATP (Błaszczyk, 2020), which is required for cAMP synthesis. Not surprisingly, previous studies assessing the 
491 impact of advanced age on cAMP expression and signaling were conducted exclusively in male rodents,

492 so it is not known whether advanced age impacts neural cAMP levels in a sex-specific manner.

493 Morphine binding to MOR results in the activation of Gai/o that primarily inhibits the activity of AC,

494 thereby reducing the ability to generate cAMP; in parallel, the $\beta \gamma$ subunits activate G-protein inwardly

495 rectifying potassium (GIRK) channels to induce hyperpolarization and decrease excitability (Law et al.,

496 2000; Nobles et al., 2005; Yudin and Rohacs, 2018). Advanced age is concomitant with increased levels

497 of neuroinflammation and greater production of reactive oxygen species (ROS), both of which have been

498 implicated in age-induced potassium channel dysfunction (Sparkman and Johnson, 2008; Sesti, 2016;

499 Lieberman et al., 2020). Consistent with this, aged Sprague Dawley rats (26-30 mos) exhibit reduced

500 potassium currents in hippocampal neurons (Alshuaib et al., 2001). Further experimentation assessing

501 the impact of advanced age and sex on GIRK channel-mediated hyperpolarization, in addition to cAMP-

502 mediated hyperpolarization, will provide a more detailed description of the impact of advanced age and

503 sex on downstream opioid signaling in the PAG.

Impact of advanced age and sex on RGS protein levels

505 G-protein activation by MOR results in the exchange of GDP for GTP (Senese et al., 2020). GTP-bound G $\alpha$

506 proteins are inactivated by hydrolysis of the GTP back to GDP, catalyzed by the intrinsic GTPase activity

507 of Ga proteins. This inactivation mechanism is modulated by the activity of Regulator of G-protein

508 signaling (RGS) proteins. RGS proteins reduce the magnitude of GPCR signaling via enhancement of

509 GTPase activity of the $\alpha$ subunit of the G-protein complex. By promoting the hydrolysis of the alpha-

510 bound GTP during the active state, RGS proteins hasten the return of the a subunit to the GDP-bound

511 inactive state (Roman and Traynor, 2011). RGS proteins play a critical role in negatively modulating

512 opioid signaling, as morphine analgesia is increased in male mice lacking RGS9-2 (Garzón et al., 2001;

513 Zachariou et al., 2003) and overexpression of RGS4 attenuates MOR signaling in reconstituted MORs in 
514 vitro (Ippolito et al., 2002). In the present study, we observed increased expression of RGS4 and RGS9-2

515 in the vIPAG of aged rats compared to adults, suggesting greater GTPase activity and thus reduced G-

516 protein signaling in the aged. Similar results were observed when the analysis was limited to MOR+ cells,

517 indicating that opioid-induced G-protein signaling is subjected to greater negative regulation in the

518 vIPAG of the aged rat. These results are consistent with Kim et al. (2005) who reported higher RGS9-2

519 protein levels in the PAG of 1-year old male rats compared to 3-week-old rats (Kim et al., 2005). In

520 humans, advanced age is associated with increased RGS4 expression in the prefrontal cortex (Rivero et

521 al., 2010), suggesting that the age-induced increase in RGS4 in our experiment may not be specific to the

522 vIPAG. These results provide a mechanism by which advanced age could decrease analgesic potency and

523 downstream cAMP signaling, although they do not provide a mechanism by which adult females

524 demonstrate lower potency and signaling than adult males.

\section{Summary and Conclusions}

526 The present studies are the first to show that sex and advanced age leads to an attenuation in vIPAG

527 opioid signaling compared to adult male rats. Taken together with our previous findings, these results

528 suggest that age- and sex-induced reductions in vIPAG MOR expression and binding, combined with

529 attenuated downstream MOR signaling, contribute to the diminished opioid potency reported in aged

530 and female rats (Fullerton et al., 2021). The results of our analyses demonstrate that aged and female

531 rats exhibit reductions in MOR expression/availability, G-protein activation, and cAMP inhibition, and

532 increased G-protein regulation by RGS proteins, each of which provides potential therapeutic targets for

533 improved pain management in the elderly.

535 The nature of the results observed also suggest potential mechanisms of action for sex and age to

536 impact analgesic potency. First, the normal ligand affinity (Kd) and lack of receptor phosphorylation 
537 suggests that unit receptor performance is normal. When combined with the observed decrease in

538 expression/availability (Bmax), this suggests that one major mechanism is a decrease in receptor

539 expression instead of a change in unit receptor performance. When considering the G protein coupling

540 analysis, since soluble regulators (like RGS proteins) are absent in this assay and the ${ }^{35} \mathrm{~S}-\mathrm{GTP} \gamma \mathrm{S}$ is non-

541 hydrolyzable, the decrease in G protein coupling potency is likely due to decreased receptor availability.

542 Downstream of the G proteins, we also observed a decrease in cAMP inhibition. This downstream effect

543 could be due to the observed increase in RGS expression, decreasing G protein activity, leading to less

544 cAMP inhibition. However, RGS expression was not increased in adult females. Overall then our results

545 suggest two major complementary mechanisms; 1 ) decreased receptor expression/availability in adult

546 females and aged males and females, and 2) increased RGS expression in aged males and females.

547 Further investigation could also uncover additional complementary sex- and age-related mechanisms

548 that help explain why opioids show lower analgesic potency in females and the aged.

551 Funding: This work was sıpported by the National Institutes of Health [Grant DA041529 AZM, Grant 552 UG3DA047717 JMS, Grant P50 MH100023 LY]; and Georgia State University [Molecular Basis of Disease 553 Fellowship EFF, Provost's Dissertation Fellowship EFF].

554 Author Contributions: AZM and EFF designed the research and wrote the paper. MK, JMS, and LY aided 555 in the design of the research. EFF, MK, and JMS performed the research, EFF, AZM, and JMS analyzed 556 the data. 


\section{References}

Abrimian, A., Kraft, T., Pan, Y.-X., 2021. Endogenous Opioid Peptides and Alternatively Spliced Mu Opioid Receptor Seven Transmembrane Carboxyl-Terminal Variants. Int. J. Mol. Sci. 22, 3779. https://doi.org/10.3390/ijms22073779

Alemany, R., Perona, J.S., Sánchez-Dominguez, J.M., Montero, E., Cañizares, J., Bressani, R., Escribá, P.V., Ruiz-Gutierrez, V., 2007. G protein-coupled receptor systems and their lipid environment in health disorders during aging. Biochim. Biophys. Acta BBA - Biomembr. 1768, 964-975. https://doi.org/10.1016/j.bbamem.2006.09.024

Alshuaib, W.B., Hasan, S.M., Cherian, S.P., Mathew, M.V., Hasan, M.Y., Fahim, M.A., 2001. Reduced potassium currents in old rat CA1 hippocampal neurons. J. Neurosci. Res. 63, 176-184. https://doi.org/10.1002/1097-4547(20010115)63:2<176::AID-JNR1009>3.0.CO;2-H

Alvarez, V.A., Arttamangkul, S., Dang, V., Salem, A., Whistler, J.L., von Zastrow, M., Grandy, D.K., Williams, J.T., 2002. $\mu$-Opioid Receptors: Ligand-Dependent Activation of Potassium Conductance, Desensitization, and Internalization. J. Neurosci. 22, 5769-5776. https://doi.org/10.1523/JNEUROSCI.2213-05769.2002

Avrampou, K., Pryce, K.D., Ramakrishnan, A., Sakloth, F., Gaspari, S., Serafini, R.A., Mitsi, V., Polizu, C., Swartz, C., Ligas, B., Richards, A., Shen, L., Carr, F.B., Zachariou, V., 2019. RGS4 Maintains Chronic Pain Symptoms in Rodent Models. J. Neurosci. 39, 8291-8304. https://doi.org/10.1523/JNEUROSCI.315418.2019

Basbaum, A.I., Clanton, C.H., Fields, H.L., 1976. Opiate and stimulus-produced analgesia: functional anatomy of a medullospinal pathway. Proc. Natl. Acad. Sci. 73, 4685-4688.

https://doi.org/10.1073/pnas.73.12.4685

Behbehani, M.M., Fields, H.L., 1979. Evidence that an excitatory connection between the periaqueductal gray and nucleus raphe magnus mediates stimulation produced analgesia. Brain Res. 170, 85-93. https://doi.org/10.1016/0006-8993(79)90942-9

Błaszczyk, J.W., 2020. Energy Metabolism Decline in the Aging Brain-Pathogenesis of Neurodegenerative Disorders. Metabolites 10, 450. https://doi.org/10.3390/metabo10110450

Bodnar, R.J., Williams, C.L., Lee, S.J., Pasternak, G.W., 1988. Role of mu 1-opiate receptors in supraspinal opiate analgesia: a microinjection study. Brain Res. 447, 25-34. https://doi.org/10.1016/00068993(88)90962-6

Bouchet, C.A., McPherson, K.B., Li, M., Traynor, J.R., Ingram, S.L., 2021. Mice Expressing Regulators of G protein Signaling-insensitive Gao Define Roles of $\mu$ Opioid Receptor $\mathrm{G} \alpha \mathrm{o}$ and $\mathrm{G} \alpha$ i Subunit Coupling in Inhibition of Presynaptic GABA Release. Mol. Pharmacol. 100, 217-223.

https://doi.org/10.1124/molpharm.121.000249

Christie, M.J., 2008. Cellular neuroadaptations to chronic opioids: tolerance, withdrawal and addiction. Br. J. Pharmacol. 154, 384-396. https://doi.org/10.1038/bjp.2008.100 
Connor, M., Christie, M.D., 1999. Opioid receptor signalling mechanisms. Clin. Exp. Pharmacol. Physiol. 26, 493-499. https://doi.org/10.1046/j.1440-1681.1999.03049.x

Dahlhamer, J., 2018. Prevalence of Chronic Pain and High-Impact Chronic Pain Among Adults - United States, 2016. MMWR Morb. Mortal. Wkly. Rep. 67. https://doi.org/10.15585/mmwr.mm6736a2

Dampier, C.D., Smith, W.R., Wager, C.G., Kim, H.-Y., Bell, M.C., Miller, S.T., Weiner, D.L., Minniti, C.P., Krishnamurti, L., Ataga, K.I., Eckman, J.R., Hsu, L.L., McClish, D., McKinlay, S.M., Molokie, R., Osunkwo, I., Smith-Whitley, K., Telen, M.J., Sickle Cell Disease Clinical Research Network (SCDCRN), 2013. IMPROVE trial: a randomized controlled trial of patient-controlled analgesia for sickle cell painful episodes: rationale, design challenges, initial experience, and recommendations for future studies. Clin. Trials Lond. Engl. 10, 319-331. https://doi.org/10.1177/1740774513475850

Dang, V.C., Napier, I.A., Christie, M.J., 2009. Two Distinct Mechanisms Mediate Acute -Opioid Receptor Desensitization in Native Neurons. J. Neurosci. 29, 3322-3327.

https://doi.org/10.1523/JNEUROSCI.4749-08.2009

de Oliveira, P.G., Ramos, M.L.S., Amaro, A.J., Dias, R.A., Vieira, S.I., 2019. Gi/o-Protein Coupled Receptors in the Aging Brain. Front. Aging Neurosci. 11. https://doi.org/10.3389/fnagi.2019.00089

Domenichiello, A.F., Ramsden, C.E., 2019. The silent epidemic of chronic pain in older adults. Prog. Neuropsychopharmacol. Biol. Psychiatry 93, 284-290. https://doi.org/10.1016/j.pnpbp.2019.04.006

Fullerton, E.F., Doyle, H.H., Murphy, A.Z., 2018. Impact of sex on pain and opioid analgesia: a review. Curr. Opin. Behav. Sci. 23, 183-190. https://doi.org/10.1016/j.cobeha.2018.08.001

Fullerton, E.F., Rubaharan, M., Karom, M.C., Hanberry, R.I., Murphy, A.Z., 2021. Advanced age attenuates the antihyperalgesic effect of morphine and decreases $\mu$-opioid receptor expression and binding in the rat midbrain periaqueductal gray in male and female rats. Neurobiol. Aging 98, 78-87. https://doi.org/10.1016/j.neurobiolaging.2020.10.020

Garnier, M., Zaratin, P.F., Ficalora, G., Valente, M., Fontanella, L., Rhee, M.-H., Blumer, K.J., Scheideler, M.A., 2003. Up-regulation of regulator of $G$ protein signaling 4 expression in a model of neuropathic pain and insensitivity to morphine. J. Pharmacol. Exp. Ther. 304, 1299-1306.

https://doi.org/10.1124/jpet.102.043471

Garzón, J., Rodríguez-Díaz, M., López-Fando, A., Sánchez-Blázquez, P., 2001. RGS9 proteins facilitate acute tolerance to mu-opioid effects: RGS9 facilitates opioid tachyphylaxis. Eur. J. Neurosci. 13, 801811. https://doi.org/10.1046/j.0953-816x.2000.01444.x

Gerber, K.J., Squires, K.E., Hepler, J.R., 2016. Roles for Regulator of G Protein Signaling Proteins in Synaptic Signaling and Plasticity. Mol. Pharmacol. 89, 273-286. https://doi.org/10.1124/mol.115.102210

Gintzler, A.R., Chakrabarti, S., 2006. Post-opioid receptor adaptations to chronic morphine; altered functionality and associations of signaling molecules. Life Sci. 79, 717-722.

https://doi.org/10.1016/j.Ifs.2006.02.016

Gintzler, A.R., Chakrabarti, S., 2004. Chronic morphine-induced plasticity among signalling molecules. Novartis Found. Symp. 261, 167-176; discussion 176-180, 191-193. 
631

632

633

634

635

636

637

638

639

640

641

642

643

644

645

646

647

648

649

650

651

652

653

654

655

656

657

658

659

660

661

662

663

664

665

Gintzler, A.R., Chakrabarti, S., 2000. Opioid tolerance and the emergence of new opioid receptorcoupled signaling. Mol. Neurobiol. 21, 21-33. https://doi.org/10.1385/MN:21:1-2:021

Groer, C.E., Schmid, C.L., Jaeger, A.M., Bohn, L.M., 2011. Agonist-directed Interactions with Specific $\beta$ Arrestins Determine $\mu$-Opioid Receptor Trafficking, Ubiquitination, and Dephosphorylation. J. Biol. Chem. 286, 31731-31741. https://doi.org/10.1074/jbc.M111.248310

Harris, R.E., Clauw, D.J., Scott, D.J., McLean, S.A., Gracely, R.H., Zubieta, J.-K., 2007. Decreased central mu-opioid receptor availability in fibromyalgia. J. Neurosci. Off. J. Soc. Neurosci. 27, 10000-10006. https://doi.org/10.1523/JNEUROSCI.2849-07.2007

Ippolito, D.L., Temkin, P.A., Rogalski, S.L., Chavkin, C., 2002. N-terminal Tyrosine Residues within the Potassium Channel Kir3 Modulate GTPase Activity of Gai. J. Biol. Chem. 277, 32692-32696.

https://doi.org/10.1074/jbc.M204407200

Jensen, T.S., Yaksh, T.L., 1986. III. Comparison of the antinociceptive action of Mu and delta opioid receptor ligands in the periaqueductal gray matter, medial and paramedial ventral medulla in the rat as studied by the microinjection technique. Brain Res. 372, 301-312. https://doi.org/10.1016/00068993(86)91138-8

Kavaliers, M., Hirst, M., Teskey, G.C., 1983. Ageing, opioid analgesia and the pineal gland. Life Sci. 32, 2279-2287. https://doi.org/10.1016/0024-3205(83)90427-7

Kelly, M.P., 2018. Cyclic nucleotide signaling changes associated with normal aging and age-related diseases of the brain. Cell. Signal. 42, 281-291. https://doi.org/10.1016/j.cellsig.2017.11.004

Kest, B., Sarton, E., Dahan, A., Fisher, D.M., 2000. Gender Differences in Opioid-mediated Analgesia. Anesthesiology 93, 539-547. https://doi.org/10.1097/00000542-200008000-00034

Kim, K.J., Moriyama, K., Han, K.R., Sharma, M., Han, X., Xie, G., Palmer, P.P., 2005. Differential expression of the regulator of $\mathrm{G}$ protein signaling RGS9 protein in nociceptive pathways of different age rats. Dev.

Brain Res. 160, 28-39. https://doi.org/10.1016/j.devbrainres.2005.08.003

Koehl, A., Hu, H., Maeda, S., Zhang, Y., Qu, Q., Paggi, J.M., Latorraca, N.R., Hilger, D., Dawson, R., Matile, H., Schertler, G.F.X., Granier, S., Weis, W.I., Dror, R.O., Manglik, A., Skiniotis, G., Kobilka, B.K., 2018.

Structure of the $\mu$-opioid receptor-G i protein complex. Nature 558, 547-552.

https://doi.org/10.1038/s41586-018-0219-7

Kramer, E., Bodnar, R.J., 1986. Age-related decrements in morphine analgesia: A parametric analysis.

Neurobiol. Aging 7, 185-191. https://doi.org/10.1016/0197-4580(86)90041-2

Lamberts, J.T., Jutkiewicz, E.M., Mortensen, R.M., Traynor, J.R., 2011. Mu-Opioid Receptor Coupling to Gao Plays an Important Role in Opioid Antinociception. Neuropsychopharmacology 36, 2041-2053. https://doi.org/10.1038/npp.2011.91

Latorre, E., Harries, L.W., 2017. Splicing regulatory factors, ageing and age-related disease. Ageing Res. Rev. 36, 165-170. https://doi.org/10.1016/j.arr.2017.04.004 
666

667

668

669

670

671

672

673

674

675

676

677

678

679

680

681

682

683

684

685

686

687

688

689

690

691

692

693

694

695

696

697

698

699

700

701

702

703

Laugwitz, K.L., Offermanns, S., Spicher, K., Schultz, G., 1993. mu and delta opioid receptors differentially couple to $\mathrm{G}$ protein subtypes in membranes of human neuroblastoma SH-SY5Y cells. Neuron 10, $233-$ 242. https://doi.org/10.1016/0896-6273(93)90314-h

Law, P.Y., Wong, Y.H., Loh, H.H., 2000. Molecular mechanisms and regulation of opioid receptor signaling. Annu. Rev. Pharmacol. Toxicol. 40, 389-430.

https://doi.org/10.1146/annurev.pharmtox.40.1.389

Lei, W., Mullen, N., McCarthy, S., Brann, C., Richard, P., Cormier, J., Edwards, K., Bilsky, E.J., Streicher, J.M., 2017. Heat-shock protein 90 (Hsp90) promotes opioid-induced anti-nociception by an ERK mitogen-activated protein kinase (MAPK) mechanism in mouse brain. J. Biol. Chem. 292, 10414-10428. https://doi.org/10.1074/jbc.M116.769489

Li, H., Wang, Z., Ma, T., Wei, G., Ni, T., 2017. Alternative splicing in aging and age-related diseases. Transl. Med. Aging 1, 32-40. https://doi.org/10.1016/j.tma.2017.09.005

Li, X., Shaqura, M., Mohamed, D., Beyer, A., Yamada, S., Mousa, S.A., Schäfer, M., 2018. Pro- versus Antinociceptive Nongenomic Effects of Neuronal Mineralocorticoid versus Glucocorticoid Receptors during Rat Hind Paw Inflammation. Anesthesiology 128, 796-809.

https://doi.org/10.1097/ALN.0000000000002087

Lieberman, O.J., Bartolini, F., Miniaci, M.C., 2020. GIRK channels in Alzheimer's disease. Aging 12, 18793-18794. https://doi.org/10.18632/aging.104026

Liu, A., Zhang, H., Qin, F., Wang, Qisheng, Sun, Q., Xie, S., Wang, Qian, Tang, Z., Lu, Z., 2018. Sex Associated Differential Expressions of the Alternatively Spliced Variants mRNA of OPRM1 in Brain Regions of C57BL/6 Mouse. Cell. Physiol. Biochem. 50, 1441-1459. https://doi.org/10.1159/000494644

Loyd, D.R., Morgan, M.M., Murphy, A.Z., 2007. Morphine Preferentially Activates the Periaqueductal Gray-Rostral Ventromedial Medullary Pathway in the Male Rat: A Potential Mechanism for Sex Differences in Antinociception. Neuroscience 147, 456-468.

https://doi.org/10.1016/j.neuroscience.2007.03.053

Loyd, D.R., Wang, X., Murphy, A.Z., 2008. Sex Differences in $\mu$-Opioid Receptor Expression in the Rat Midbrain Periaqueductal Gray Are Essential for Eliciting Sex Differences in Morphine Analgesia. J. Neurosci. 28, 14007-14017. https://doi.org/10.1523/JNEUROSCI.4123-08.2008

Ma, Q.P., Han, J.S., 1991. Naloxone blocks the release of opioid peptides in periaqueductal gray and N. accumbens induced by intra-amygdaloid injection of morphine. Peptides 12, 1235-1238. https://doi.org/10.1016/0196-9781(91)90200-9

Maarrawi, J., Peyron, R., Mertens, P., Costes, N., Magnin, M., Sindou, M., Laurent, B., Garcia-Larrea, L., 2007. Differential brain opioid receptor availability in central and peripheral neuropathic pain. Pain 127, 183-194. https://doi.org/10.1016/j.pain.2006.10.013

Manchikanti, L., Fellows, B., Ailinani, H., Pampati, V., 2010. Therapeutic use, abuse, and nonmedical use of opioids: a ten-year perspective. Pain Physician 13, 401-435.

Martin, W.R., 1963. Analgesic and antipyretic drugs in Physiological Pharmacology. Pharmacol Rev, Academic Press, NY 275-312. 
Melkes, B., Markova, V., Hejnova, L., Novotny, J., 2020. $\beta$-Arrestin 2 and ERK1/2 Are Important Mediators Engaged in Close Cooperation between TRPV1 and $\mu$-Opioid Receptors in the Plasma Membrane. Int. J. Mol. Sci. 21, 4626. https://doi.org/10.3390/ijms21134626

Morgan, M.M., Fossum, E.N., Stalding, B.M., King, M.M., 2006. Morphine antinociceptive potency on chemical, mechanical, and thermal nociceptive tests in the rat. J. Pain 7, 358-366. https://doi.org/10.1016/j.jpain.2005.12.009

Morgan, M.M., Heinricher, M.M., Fields, H.L., 1992. Circuitry linking opioid-sensitive nociceptive modulatory systems in periaqueductal gray and spinal cord with rostral ventromedial medulla. Neuroscience 47, 863-871. https://doi.org/10.1016/0306-4522(92)90036-2

Mousa, S.A., Zhang, Q., Sitte, N., Ji, R., Stein, C., 2001. beta-Endorphin-containing memory-cells and muopioid receptors undergo transport to peripheral inflamed tissue. J. Neuroimmunol. 115, 71-78. https://doi.org/10.1016/s0165-5728(01)00271-5

Naples, J.G., Gellad, W.F., Hanlon, J.T., 2016. The Role of Opioid Analgesics in Geriatric Pain Management. Clin. Geriatr. Med. 32, 725-735. https://doi.org/10.1016/j.cger.2016.06.006

Narayan, A., Hunkele, A., Xu, J., Bassoni, D.L., Pasternak, G.W., Pan, Y.-X., 2021. Mu Opioids Induce Biased Signaling at the Full-Length Seven Transmembrane C-Terminal Splice Variants of the mu Opioid Receptor Gene, Oprm1. Cell. Mol. Neurobiol. 41, 1059-1074. https://doi.org/10.1007/s10571-02000973-5

Nobles, M., Benians, A., Tinker, A., 2005. Heterotrimeric G proteins precouple with $G$ protein-coupled receptors in living cells. Proc. Natl. Acad. Sci. U. S. A. 102, 18706-18711. https://doi.org/10.1073/pnas.0504778102

Ogier-Denis, E., Pattingre, S., El Benna, J., Codogno, P., 2000. Erk1/2-dependent phosphorylation of Galpha-interacting protein stimulates its GTPase accelerating activity and autophagy in human colon cancer cells. J. Biol. Chem. 275, 39090-39095. https://doi.org/10.1074/jbc.M006198200

Oldfield, S., Braksator, E., Rodriguez-Martin, I., Bailey, C.P., Donaldson, L.F., Henderson, G., Kelly, E., 2008. C-terminal splice variants of the mu-opioid receptor: existence, distribution and functional characteristics. J. Neurochem. 104, 937-945. https://doi.org/10.1111/j.1471-4159.2007.05057.x

Pan, Y.-X., Xu, J., Bolan, E., Moskowitz, H.S., Xu, M., Pasternak, G.W., 2005. Identification of four novel exon 5 splice variants of the mouse mu-opioid receptor gene: functional consequences of C-terminal splicing. Mol. Pharmacol. 68, 866-875. https://doi.org/10.1124/mol.105.011858

Pasternak, D.A., Pan, L., Xu, J., Yu, R., Xu, M.-M., Pasternak, G.W., Pan, Y.-X., 2004. Identification of three new alternatively spliced variants of the rat mu opioid receptor gene: dissociation of affinity and efficacy. J. Neurochem. 91, 881-890. https://doi.org/10.1111/j.1471-4159.2004.02767.x

Patel, K.V., Guralnik, J.M., Dansie, E.J., Turk, D.C., 2013. Prevalence and Impact of Pain among Older Adults in the United States: Findings from the 2011 National Health and Aging Trends Study. Pain 154. https://doi.org/10.1016/j.pain.2013.07.029 
Popiolek-Barczyk, K., Makuch, W., Rojewska, E., Pilat, D., Mika, J., 2014. Inhibition of intracellular signaling pathways NF-KB and MEK1/2 attenuates neuropathic pain development and enhances morphine analgesia. Pharmacol. Rep. PR 66, 845-851. https://doi.org/10.1016/j.pharep.2014.05.001

Prostran, M., Vujović, K.S., Vučković, S., Medić, B., Srebro, D., Divac, N., Stojanović, R., Vujović, A., Jovanović, L., Jotić, A., Cerovac, N., 2016. Pharmacotherapy of Pain in the Older Population: The Place of Opioids. Front. Aging Neurosci. 8. https://doi.org/10.3389/fnagi.2016.00144

Psifogeorgou, K., Papakosta, P., Russo, S.J., Neve, R.L., Kardassis, D., Gold, S.J., Zachariou, V., 2007. RGS92 is a negative modulator of $\mu$-opioid receptor function: RGS9-2 modulates $\mu$-opioid receptor responsiveness. J. Neurochem. 103, 617-625. https://doi.org/10.1111/j.1471-4159.2007.04812.x

Puri, S.K., Volicer, L., 1981. Age-related changes of cyclic nucleotide levels in rat brain regions. Mech. Ageing Dev. 15, 239-242. https://doi.org/10.1016/0047-6374(81)90132-9

Reddy, K.S.K., Naidu, M.U.R., Rani, P.U., Rao, T.R.K., 2012. Human experimental pain models: A review of standardized methods in drug development. J. Res. Med. Sci. Off. J. Isfahan Univ. Med. Sci. 17, 587-595.

Rivero, G., Gabilondo, A.M., García-Sevilla, J.A., La Harpe, R., Morentín, B., Javier Meana, J., 2010. Characterization of regulators of G-protein signaling RGS4 and RGS10 proteins in the postmortem human brain. Neurochem. Int. 57, 722-729. https://doi.org/10.1016/j.neuint.2010.08.008

Roman, D.L., Traynor, J.R., 2011. Regulators of G Protein Signaling (RGS) Proteins as Drug Targets: Modulating G-Protein-Coupled Receptor (GPCR) Signal Transduction: Miniperspective. J. Med. Chem. 54, 7433-7440. https://doi.org/10.1021/jm101572n

Santhappan, R., Crowder, A.T., Gouty, S., Cox, B.M., Côté, T.E., 2015. Mu opioid receptor activation enhances regulator of $\mathrm{G}$ protein signaling 4 association with the mu opioid receptor/G protein complex in a GTP-dependent manner. J. Neurochem. 135, 76-87. https://doi.org/10.1111/jnc.13222

Satoh, M., Kubota, A., Iwama, T., Wada, T., Yasui, M., Fujibayashi, K., Takagi, H., 1983. Comparison of analgesic potencies of $\mathrm{mu}$, delta and kappa agonists locally applied to various CNS regions relevant to analgesia in rats. Life Sci. 33 Suppl 1, 689-692. https://doi.org/10.1016/0024-3205(83)90596-9

Schulz, S., Mayer, D., Pfeiffer, M., Stumm, R., Koch, T., Höllt, V., 2004. Morphine induces terminal $\mu-$ opioid receptor desensitization by sustained phosphorylation of serine-375. EMBO J. 23, 3282-3289. https://doi.org/10.1038/sj.emboj.7600334

Senese, N.B., Kandasamy, R., Kochan, K.E., Traynor, J.R., 2020. Regulator of G-Protein Signaling (RGS) Protein Modulation of Opioid Receptor Signaling as a Potential Target for Pain Management. Front. Mol. Neurosci. 13. https://doi.org/10.3389/fnmol.2020.00005

Sesti, F., 2016. Oxidation of K+ Channels in Aging and Neurodegeneration. Aging Dis. 7, 130-135. https://doi.org/10.14336/AD.2015.0901

Shaqura, M., Li, X., Al-Khrasani, M., Shakibaei, M., Tafelski, S., Fürst, S., Beyer, A., Kawata, M., Schäfer, M., Mousa, S.A., 2016a. Membrane-bound glucocorticoid receptors on distinct nociceptive neurons as potential targets for pain control through rapid non-genomic effects. Neuropharmacology 111, 1-13. https://doi.org/10.1016/j.neuropharm.2016.08.019 
Shaqura, M., Li, X., Al-Madol, M.A., Tafelski, S., Beyer-Koczorek, A., Mousa, S.A., Schäfer, M., $2016 b$. Acute mechanical sensitization of peripheral nociceptors by aldosterone through non-genomic activation of membrane bound mineralocorticoid receptors in naive rats. Neuropharmacology 107, 251261. https://doi.org/10.1016/j.neuropharm.2016.03.032

Shaqura, M.A., Zöllner, C., Mousa, S.A., Stein, C., Schäfer, M., 2004. Characterization of mu opioid receptor binding and $\mathrm{G}$ protein coupling in rat hypothalamus, spinal cord, and primary afferent neurons during inflammatory pain. J. Pharmacol. Exp. Ther. 308, 712-718.

https://doi.org/10.1124/jpet.103.057257

Sparkman, N.L., Johnson, R.W., 2008. Neuroinflammation Associated with Aging Sensitizes the Brain to the Effects of Infection or Stress. Neuroimmunomodulation 15, 323-330.

https://doi.org/10.1159/000156474

Sullivan, M.D., Edlund, M.J., Fan, M.-Y., DeVries, A., Braden, J.B., Martin, B.C., 2010. Risks for possible and probable opioid misuse among recipients of chronic opioid therapy in commercial and medicaid insurance plans: The TROUP Study. Pain 150, 332-339. https://doi.org/10.1016/j.pain.2010.05.020

Thompson, S.J., Pitcher, M.H., Stone, L.S., Tarum, F., Niu, G., Chen, X., Kiesewetter, D.O., Schweinhardt, P., Bushnell, M.C., 2018. Chronic neuropathic pain reduces opioid receptor availability with associated anhedonia in rat. Pain 159, 1856-1866. https://doi.org/10.1097/j.pain.0000000000001282

Titus, D.J., Furones, C., Kang, Y., Atkins, C.M., 2013. Age-dependent alterations in cAMP signaling contribute to synaptic plasticity deficits following traumatic brain injury. Neuroscience 231, 182-194. https://doi.org/10.1016/j.neuroscience.2012.12.002

Verzillo, V., Madia, P.A., Liu, N.-J., Chakrabarti, S., Gintzler, A.R., 2014. Mu-opioid receptor splice variants: sex-dependent regulation by chronic morphine. J. Neurochem. 130, 790-796. https://doi.org/10.1111/jnc.12768

Viganò, D., Rubino, T., Di Chiara, G., Ascari, I., Massi, P., Parolaro, D., 2003. $\mu$ opioid receptor signaling in morphine sensitization. Neuroscience 117, 921-929. https://doi.org/10.1016/S0306-4522(02)00825-4

Wang, K., Wu, D., Zhang, H., Das, A., Basu, M., Malin, J., Cao, K., Hannenhalli, S., 2018. Comprehensive map of age-associated splicing changes across human tissues and their contributions to age-associated diseases. Sci. Rep. 8, 10929. https://doi.org/10.1038/s41598-018-29086-2

Wang, Y.-J., Huang, P., Blendy, J.A., Liu-Chen, L.-Y., 2014. Brain region- and sex-specific alterations in DAMGO-stimulated [ ${ }^{35} \mathrm{~S}$ ] GTPYS binding in mice with Oprm1 A112G: A118G SNP on MOPR activation. Addict. Biol. 19, 354-361. https://doi.org/10.1111/j.1369-1600.2012.00484.x

Wattiez, A.-S., Walder, R.Y., Sande, C.M., White, S.R., Hammond, D.L., 2017. Peripheral inflammatory injury alters the relative abundance of $\mathrm{G} \alpha$ subunits in the dorsal horn of the spinal cord and in the rostral ventromedial medulla of male rats. Mol. Pain 13, 1744806917715210.

https://doi.org/10.1177/1744806917715210

Webster, G.W., Shuster, L., Eleftheriou, B.E., 1976. Morphine analgesia in mice of different ages. Exp. Aging Res. 2, 221-233. https://doi.org/10.1080/03610737608257178 
Wolozin, B.L., Pasternak, G.W., 1981. Classification of multiple morphine and enkephalin binding sites in the central nervous system. Proc. Natl. Acad. Sci. 78, 6181-6185. https://doi.org/10.1073/pnas.78.10.6181

Young, L.T., Warsh, J.J., Li, P.P., Siu, K.P., Becker, L., Gilbert, J., Hornykiewicz, O., Kish, S.J., 1991. Maturational and aging effects on guanine nucleotide binding protein immunoreactivity in human brain. Brain Res. Dev. Brain Res. 61, 243-248. https://doi.org/10.1016/0165-3806(91)90137-8

Yu, Y., Zhang, L., Yin, X., Sun, H., Uhl, G.R., Wang, J.B., 1997. $\mu$ Opioid Receptor Phosphorylation, Desensitization, and Ligand Efficacy*. J. Biol. Chem. 272, 28869-28874. https://doi.org/10.1074/jbc.272.46.28869

Yudin, Y., Rohacs, T., 2018. Inhibitory Gi/O-coupled receptors in somatosensory neurons: Potential therapeutic targets for novel analgesics. Mol. Pain 14, 1744806918763646. https://doi.org/10.1177/1744806918763646

Zachariou, V., Georgescu, D., Sanchez, N., Rahman, Z., DiLeone, R., Berton, O., Neve, R.L., Sim-Selley, L.J., Selley, D.E., Gold, S.J., Nestler, E.J., 2003. Essential role for RGS9 in opiate action. Proc. Natl. Acad. Sci. 100, 13656-13661. https://doi.org/10.1073/pnas.2232594100

Zhang, J., Ferguson, S.S.G., Barak, L.S., Bodduluri, S.R., Laporte, S.A., Law, P.-Y., Caron, M.G., 1998. Role for $G$ protein-coupled receptor kinase in agonist-specific regulation of -opioid receptor responsiveness. Proc. Natl. Acad. Sci. 95, 7157-7162. https://doi.org/10.1073/pnas.95.12.7157

Zhang, L., Yu, Y., Mackin, S., Weight, F.F., Uhl, G.R., Wang, J.B., 1996. Differential $\mu$ Opiate Receptor Phosphorylation and Desensitization Induced by Agonists and Phorbol Esters (*). J. Biol. Chem. 271, 11449-11454. https://doi.org/10.1074/jbc.271.19.11449

Zhang, Y., Du, L.N., Wu, G.C., Cao, X.D., 1998. Modulation of intrathecal morphine-induced immunosuppression by microinjection of naloxone into periaqueductal gray. Zhongguo Yao Li Xue Bao 19, 519-522.

Zollner, C., Shaqura, M.A., Bopaiah, C.P., Mousa, S., Stein, C., Schafer, M., 2003. Painful inflammationinduced increase in mu-opioid receptor binding and G-protein coupling in primary afferent neurons. Mol. Pharmacol. 64, 202-210. https://doi.org/10.1124/mol.64.2.202 
Fig. 1. Saturation binding curve of bound [3H]DAMGO (A). No significant effect of age or sex was observed in MOR affinity $\left(K_{d}\right)(B)$. MOR availability $\left(B_{\max }\right)$ was significantly lower in aged males compared to adult males $(C)$. Adult females, aged males, and aged females exhibited reduced MOR binding potential $\left(B_{\max } / K_{d}\right)$ compared to adult males, indicating attenuated agonist interaction at the receptor level (D). ns, not significant. *Significant difference between adult and aged males, or adult males and adult females; $p<0.05$ calculated by Tukey's post hoc test. Graphs indicate mean \pm SEM. Values indicate $\%$ change from adult male.

857 Fig 2. $\left[{ }^{35}\right.$ S $]$ GTP $\gamma$ S binding curve of agonist-stimulated GTP $\gamma$ S binding (A). No significant effect of age or 858 sex was observed in $\mathrm{E}_{\max }(\mathrm{B})$. Aged males, adult females, and aged females exhibited increased $\mathrm{EC}_{50}$ 859 values compared to adult males, indicating that adult males have the greatest potency (C). Aged males, 860 adult females, and aged females exhibited reduced G-protein activation efficiency $\left(E_{\max } / E_{50}\right)$ compared 861 to adult males, indicating attenuated G-protein signaling (D). ns, not significant. *Significant difference 862 between adult and aged males, or adult males and adult females; $p<0.05$ calculated by Tukey's post hoc 863 test. Graphs indicate mean \pm SEM. Values indicate $\%$ change from adult male.

864 Fig 3. No significant impact of advanced age or biological sex on the ratio of phosphorylated MOR/ total 865 MOR. ns, not significant. Graph indicates mean \pm SEM. Values indicate $\%$ change from adult male.

866 Fig 4. TR-FRET immunoassay showing \% change from FSK stimulated baseline and DAMGO inhibited CAMP (CAMP levels are inversely proportional to TR-FRET signal). Adult males exhibited the highest level of agonist-dependent \% change in CAMP (A). Aged males and females exhibited reduced agonistdependent CAMP inhibition compared to adult males, indicating attenuated downstream opioid signaling (B). *Significant difference between adult and aged males, or adult males and adult females; $p<0.05$ calculated by Tukey's post hoc test. Graphs indicate mean \pm SEM. Values indicate $\%$ change from 872 FSK baseline.

873 Fig 5. mRNA expression of RGS4 (A) and RGS9-2 (B) in the vIPAG was significantly greater in aged rats compared to adults. mRNA expression of RGS4 (C) and RGS9-2 (D) on MOR+ cells in the vIPAG was significantly greater in aged rats compared to adults. (E) Photomicrograph of RGS expression compared an adult male and an aged male PAG section. *Significant difference between adults and aged rats; $p<0.05$ calculated by $2 \times 2$ ANOVA. Graphs indicate mean \pm SEM.

Fig 6. Model and table of MOR signaling impairments in the vIPAG of the aged and female rat. Aged and female rats exhibit decreased MOR binding potential, decreased G-protein activation, and decreased CAMP inhibition, while aged rats alone demonstrate increased RGS expression. No impact of age or sex 
A

MOR Saturation Binding

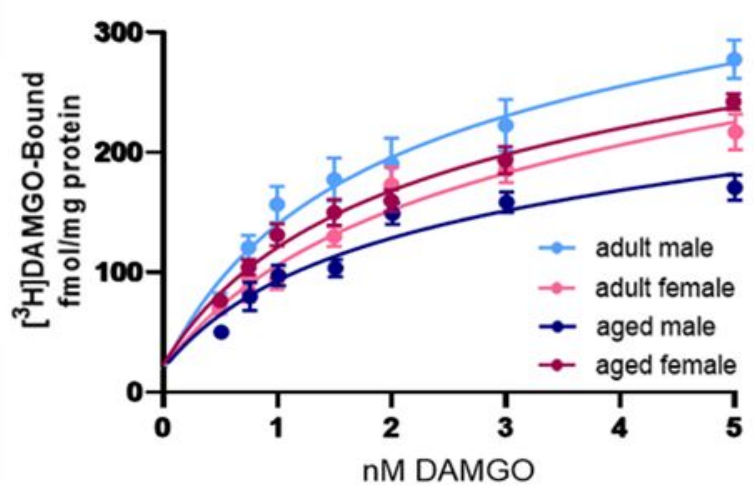

C

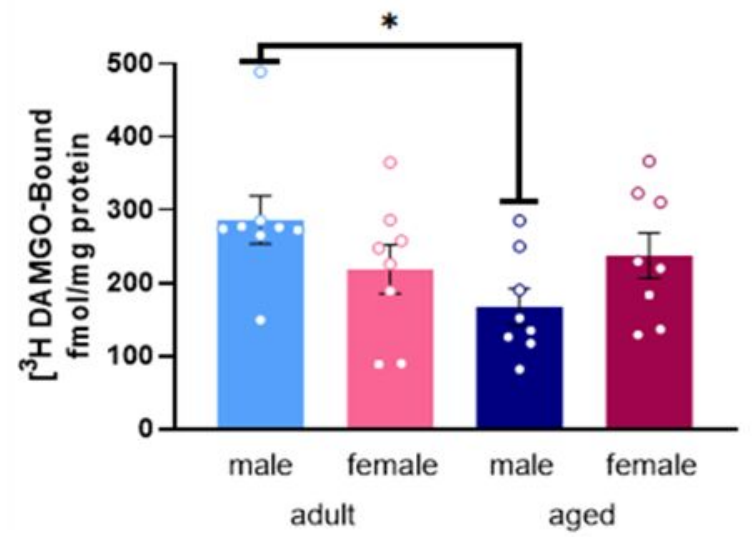

B

MOR Affinity $\left(K_{d}\right)$

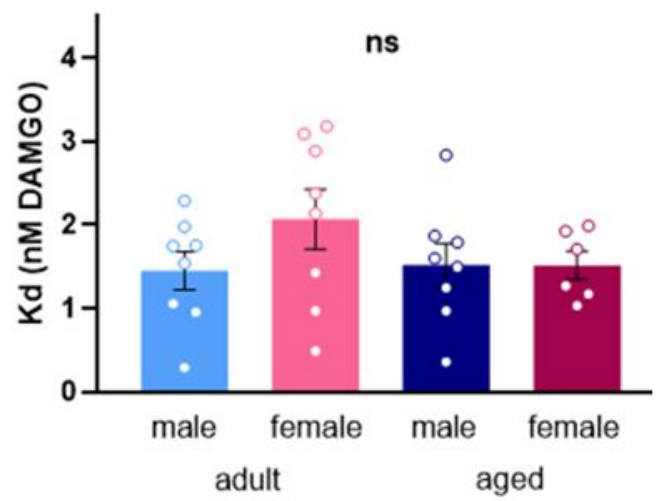

D MOR Binding Potential

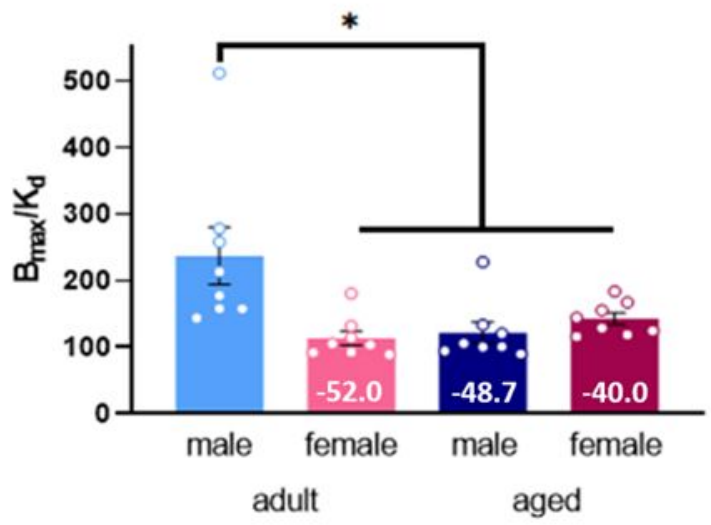


A

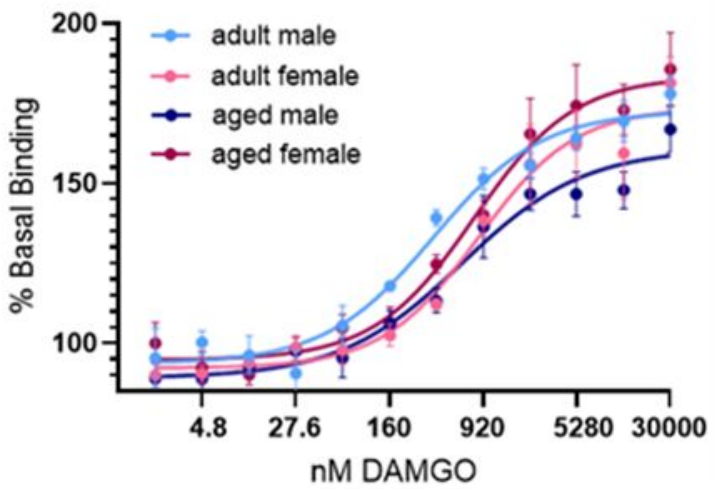

C

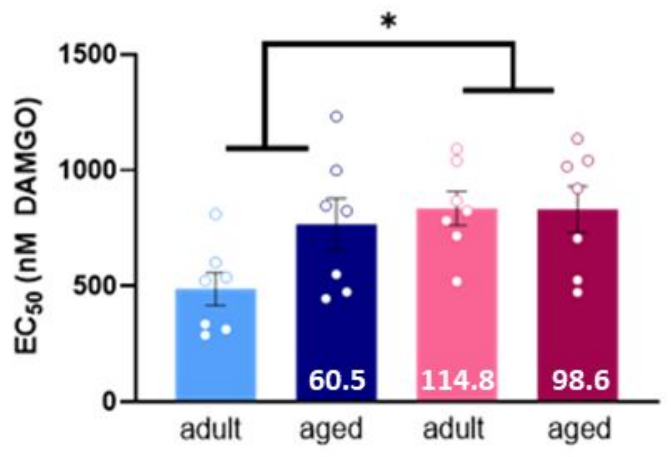

male
B G-protein efficacy $\left(E_{\max }\right)$

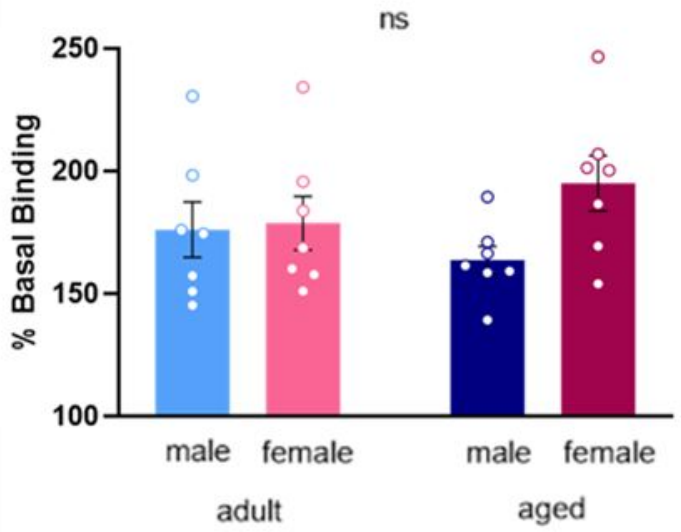

D G-protein activation efficiency

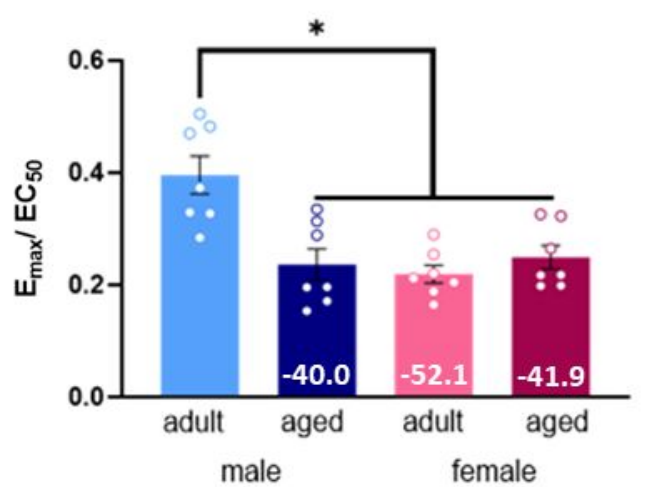


Phosphorylated MOR

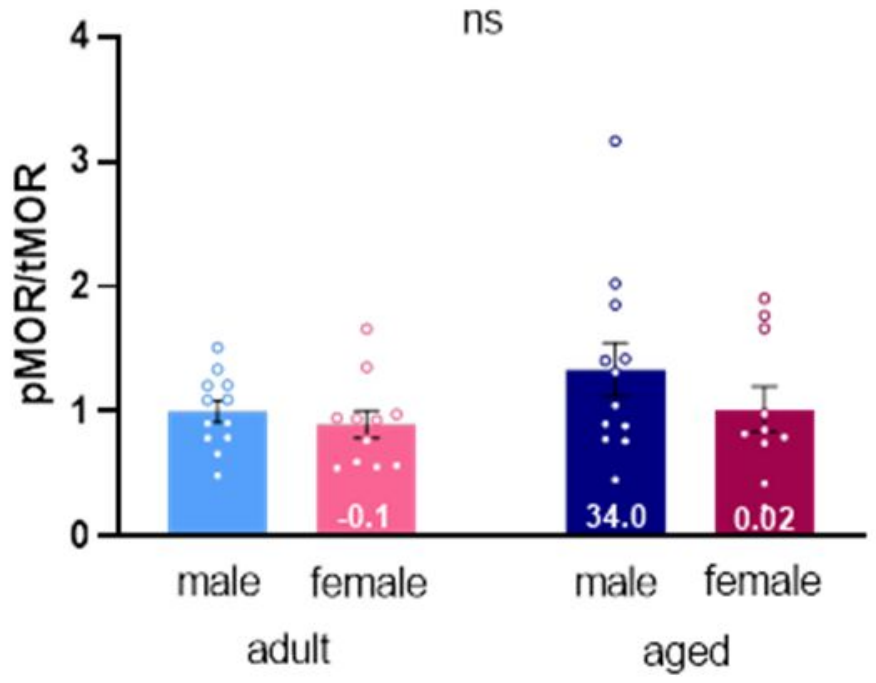




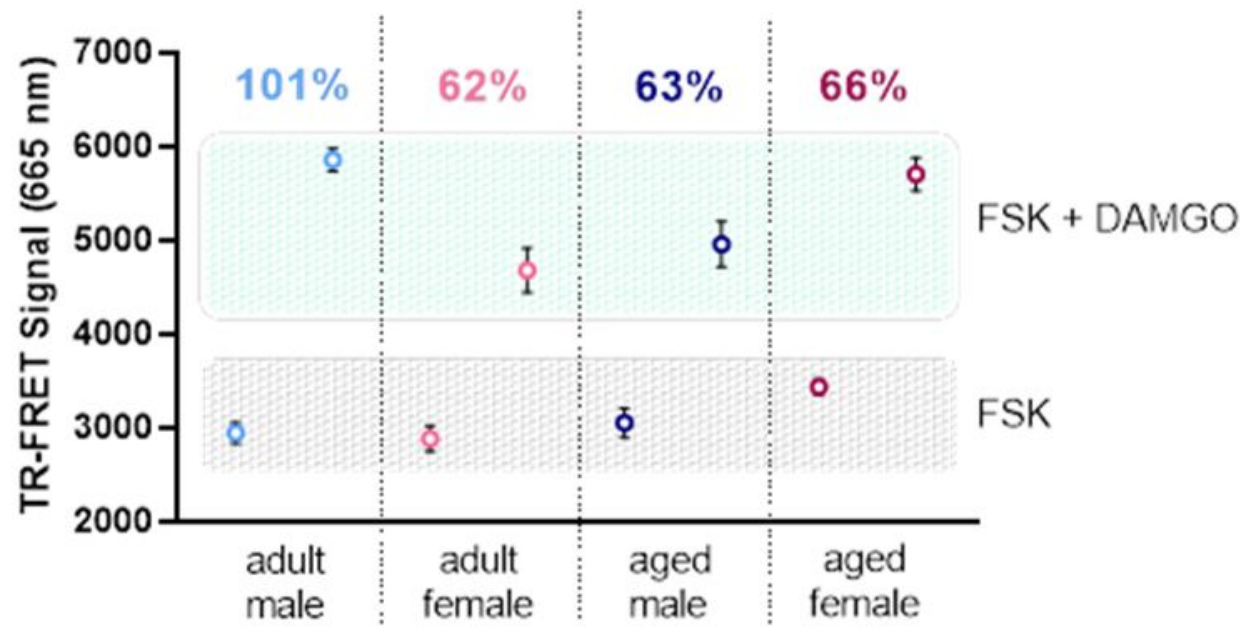

B

Agonist-dependent cAMP inhibition

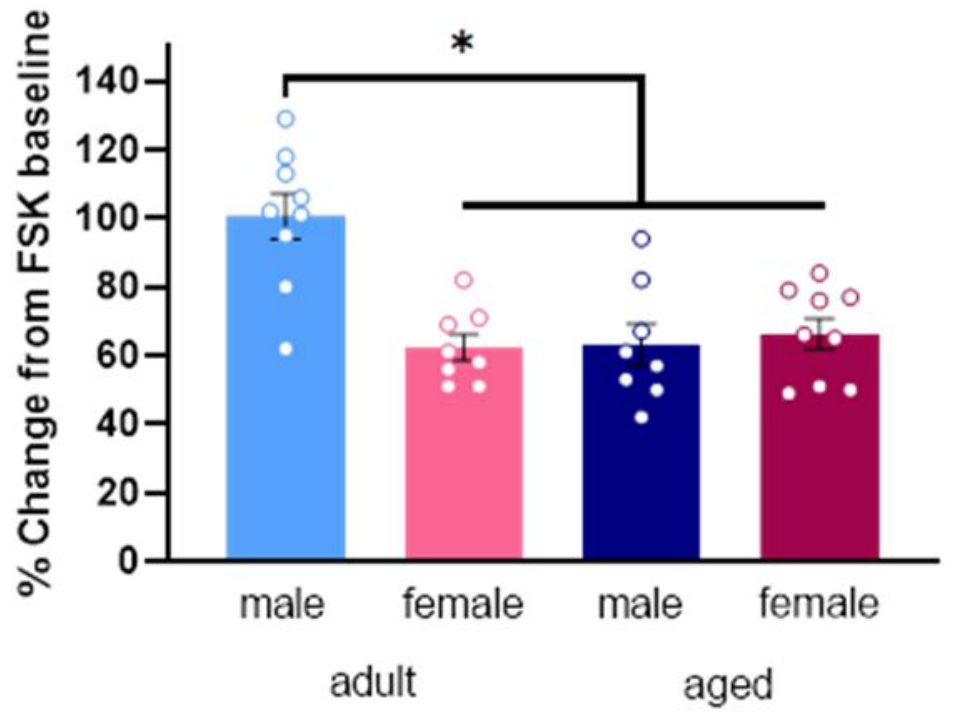


A

VIPAG RGS4 expression

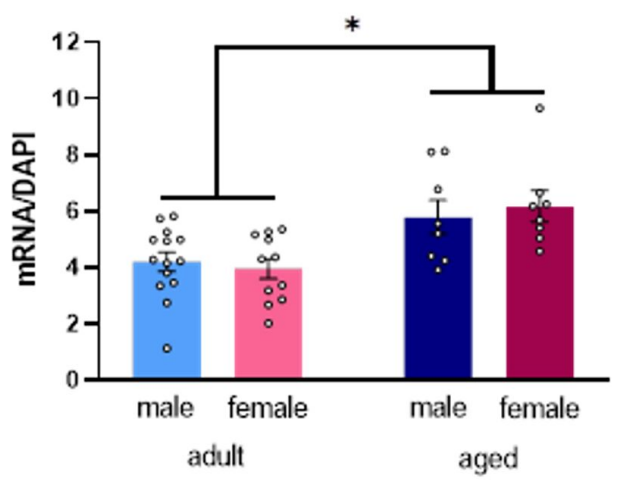

C MOR+RGS4 expression

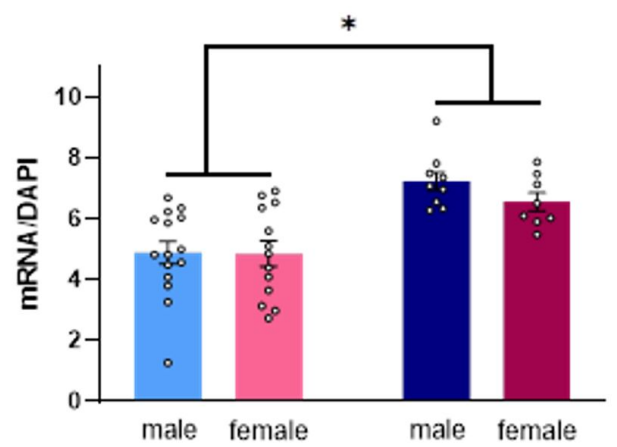

adult

aged
B

VIPAG RGS9-2 expression

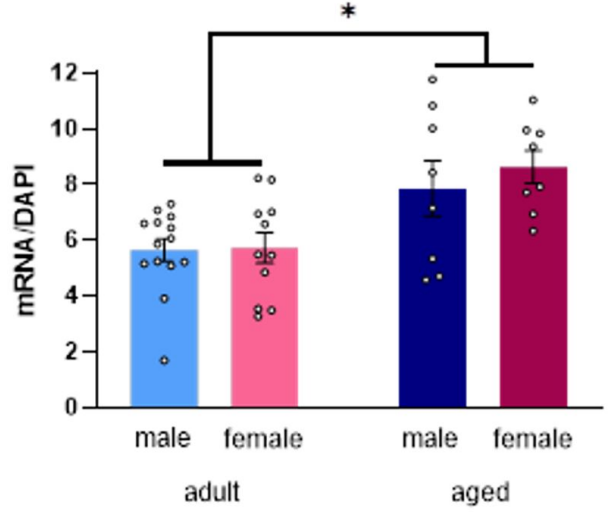

D MOR+ RGS9-2 expression

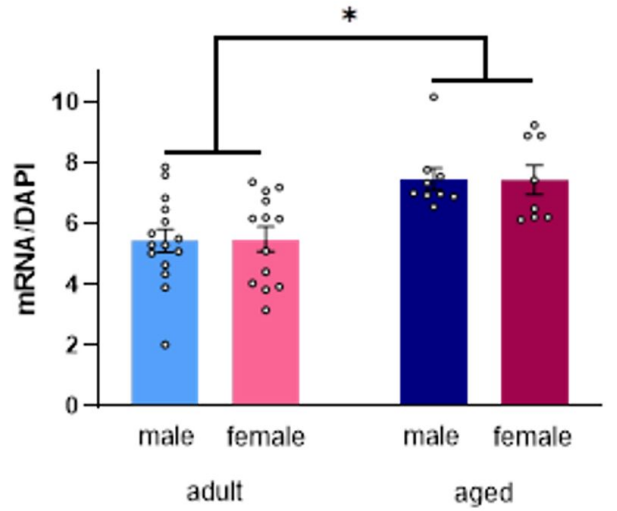

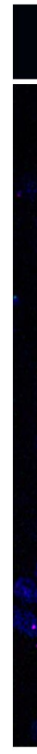

+ OPRM1 + RGS4 + RGS9-2 
Age-induced changes in PAG MOR signaling
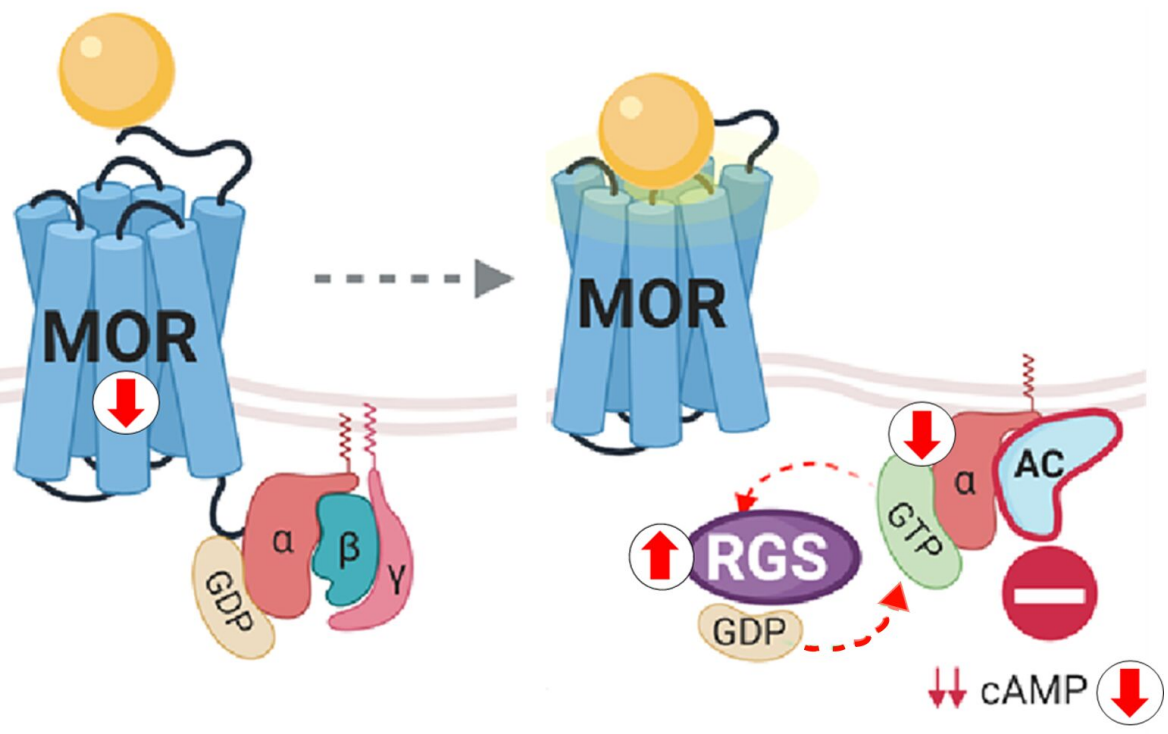

Morphine Binding G-Protein MOR cAMP RGS

\begin{tabular}{|c|c|c|c|c|c|c|}
\hline & Potency & Potential & Activation & Phosphor. & Inhibition & mRNA \\
\hline Adult $\precsim$ & $=$ & $=$ & $=$ & $=$ & $=$ & $=$ \\
\hline Adult 우 & $\downarrow$ & $\downarrow$ & $\downarrow$ & $=$ & $\downarrow$ & $=$ \\
\hline Aged $\sigma^{\pi}$ & $\downarrow$ & $\downarrow$ & $\downarrow$ & $=$ & $\downarrow$ & $\uparrow$ \\
\hline Aged ㅇ & $\downarrow$ & $\downarrow$ & $\downarrow$ & $=$ & $\downarrow$ & $\uparrow$ \\
\hline
\end{tabular}

